Marquette University

e-Publications@Marquette

Biomedical Engineering Faculty Research and

Publications

Biomedical Engineering, Department of

7-1-2010

Visual, Motor and Attentional Influences on

Proprioceptive Contributions to Perception of Hand Path Rectilinearity during Reaching

Robert A. Scheidt

Marquette University, robert.scheidt@marquette.edu

Kyle P. Lillis

Marquette University

Scott J. Emerson

Marquette University

Accepted version. Experimental Brain Research, Vol. 204, No. 2 (July 2010): 239-254. DOI. (C) 2010 Springer. Used with permission.

Shareable Link. Provided by the Springer Nature SharedIt content-sharing initiative. 


\title{
Visual, Motor and Attentional Influences on Proprioceptive Contributions to Perception of Hand Path Rectilinearity during Reaching
}

\author{
Robert A. Scheidt \\ Department of Biomedical Engineering, Marquette University \\ Milwaukee, WI \\ Department of Physical Medicine and Rehabilitation, \\ Northwestern University Medical School \\ Chicago, IL \\ Kyle P. Lillis \\ Department of Biomedical Engineering, Marquette University \\ Milwaukee, WI \\ Scott J. Emerson \\ Department of Biomedical Engineering, Marquette University \\ Milwaukee, WI
}

\begin{abstract}
:
We examined how proprioceptive contributions to perception of hand path straightness are influenced by visual, motor and attentional sources of performance variability during horizontal planar reaching. Subjects held the handle of a robot that constrained goal-directed movements of the hand to


paths of controlled curvature. Subjects attempted to detect the presence of hand path curvature during both active (subject-driven) and passive (robotdriven) movements that either required active muscle force production or not. Subjects were less able to discriminate curved from straight paths when actively reaching for a target vs. when the robot moved their hand through the same curved paths. This effect was especially evident during robot-driven movements requiring concurrent activation of lengthening but not shortening muscles. Subjects were less likely to report curvature and were more variable in reporting when movements appeared straight in a novel "visual channel" condition previously shown to block adaptive updating of motor commands in response to deviations from a straight-line hand path. Similarly compromised performance was obtained when subjects simultaneously performed a distracting secondary task (key pressing with the contralateral hand). The effects compounded when these last two treatments were combined. It is concluded that environmental, intrinsic and attentional factors all impact the ability to detect deviations from a rectilinear hand path during goal-directed movement by decreasing proprioceptive contributions to limb state estimation. In contrast, response variability increased only in experimental conditions thought to impose additional attentional demands on the observer. Implications of these results for perception and other sensorimotor behaviors are discussed.

Keywords: proprioception, vision, dual task attention, multisensory integration, arm movement, human.

\section{Introduction}

Uncertainty pervades our interactions with the world for at least three reasons. Action outcomes are unpredictable because the limb's environment is variable and nonstationary and thus, uncertainty arises from external sources. Internal factors also contribute to uncertainty because repeated application of identical sensory stimuli induce variable neural responses (cf. Cordo et al, 1996; Ribot-Ciscar et al., 2000) and because the intrinsic variability of motor commands increases with effort (Sutton and Sykes, 1967; Schmidt et al., 1979; Slifkin and Newell, 2000; Hamilton et al., 2004). Finally, people often try to multitask repetitive motor tasks, and so the attention paid to each may vary over time. To what extent do external, internal and attentional factors influence how we perceive and interact with the world?

Experimental Brain Research, Vol. 204, No. 2 (July 2010): pg. 239-254. DOI. This article is (C Springer and permission has been granted for this version to appear in e-Publications@Marquette. Springer does not grant permission for this article to be further copied/distributed or hosted elsewhere without the express permission from Springer. 
If performance accuracy is to be preserved despite variablybiased noise sources, then the neural mechanisms mediating sensorimotor control must be adaptive. Adaptation requires accurate estimates of the physical state of the moving limb (eg. joint configuration and its rate of change) so that deviations from desired values may be predicted and corrected (Shadmehr and Mussa-Ivaldi, 1994; Lackner and Dizio, 1994, Dizio and Lackner, 2000; Franklin et al 2003; Ghez et al., 1995, 1999; Sainburg et al., 1995; Scheidt et al., 2001; Smith et al., 2006; Thoroughman and Shadmehr, 2000; Wolpert et al., 1994, 1995a, 1995b). Limb state estimates arise from multiple sensory modalities including vision (Ghez et al 1995), the set of mechanoreceptors that contribute to proprioception (Gordon et al., 1995), as well as from "efference copy" and a forward model of the limb and its environment (Wolpert et al., 1995a; Nelson, 1996; Desmurget and Grafton, 2000; Gritsenko et al., 2007). Theory and experiment both suggest that the brain combines information from multiple noisy sources in inverse proportion to their respective variances such that variability in the composite state estimate is minimized; This hypothesis has been supported by several studies of multisensory perception (Ghahramani, 1995, 1997; Beers et al 1999; Ernst and Banks 2002). A similar approach including expectations of environmental variability may contribute to adaptive aiming of goaldirected horizontal planar reaching (Koerding and Wolpert, 2004).

Despite the availability of multiple sources of state information, studies of people with impaired or absent proprioception have found this sense to be critical for proper planning and execution of goaldirected reaching (Sainburg, et al 1995; Zackowski et al., 2004; Scheidt and Stoeckmann, 2007; see also Sober and Sabes, 2003). Muscle spindle afferents are important proprioceptors because they provide a mixed encoding of muscle length and rate of length change (Matthews, 1963; Hagbarth and Valbo, 1969; Houk et al., 1981; Sittig et al., 1987; Cordo et al., 1994; Roll and Gilhodes, 1995; Verschueren et al., 1999; cf. Houk and Rymer, 1981; Hasan, 1983) and contribute importantly to the sense of limb position and movement (Roll and Gilhodes, 1995; Capaday and Cooke, 1981; Cordo et al., 1994; McCloskey, 1973; Gandevia 1996). External, internal and attentional sources of variability influence muscle spindle activity: Spindle sensitivity varies with kinetic demands of active movements (Dufresne et al., 1980; Matthews, 1986; Sinkjaer, et al., 1996; Kearney et al., 
1999). Spindle activity is sensitive to the activation state (and thus "motor noise") of both the alpha and gamma motor systems (cf. Cordo et al 1996). Proprioceptive information is subject to inhibition during and in anticipation of - active movement (Voss et al., 2006, 2008; Williams and Chapman 2000). Animal studies have revealed that inhibition of input to primary afferent pathways is mediated presynaptically via descending commands during active movement (cat: Ghez and Pisa, 1972; monkey: Seki et al., 2003); this may be an important mechanism of central regulation of afferent information transformation within the motor periphery (cf. Perreault 2008). Spindle activity is also modulated by performance of attentiondiverting tasks like mental arithmetic and the execution of an isometric task with another limb (Ribot-Ciscar et al., 2000). Such findings may have widespread behavioral significance because any factor that directly influences mechanoreceptor information transduction must affect all behaviors that depend on these sources for limb state information, including both perception and motor learning (cf. Taylor and Thoroughman 2006, 2007; see also Ingram et al. 2000; Redding et al. 1992).

Here we examine how external, intrinsic and attentional sources of performance variability influence proprioceptive contributions to limb state perception during rapid, point-to-point, horizontal planar arm movements (i.e. reaching). We do so because hand-path is an important regulated feature of horizontal reaching (Scheidt et al., 2000) with trajectories normally being straight and smooth (Morasso 1981): When an unexpected mechanical perturbation displaces the hand from its intended trajectory, path rectilinearity is rapidly recovered by an adaptive, feed-forward control mechanism (i.e., motor adaptation) (Lackner and Dizio 1994; Shadmehr and Mussa-Ivaldi, 1994). This rectilinearity is sacrificed when visual feedback is distorted such that curved paths appear straight (Wolpert et al., 1995b; Flanagan and Rao, 1995; Dingwell et al., 2002) and thus visual influences are thought to dominate proprioceptive cues during adaptation. In one recent adaptation study, subjects effectively ignored proprioceptive cues related to hand path direction errors when vision was manipulated such that the moving hand always appeared on the straight-line path between initial and intended positions (the cursor was constrained within a virtual "visual channel"; Scheidt et al., 2005). Because visual feedback of directional variability was effectively

Experimental Brain Research, Vol. 204, No. 2 (July 2010): pg. 239-254. DOI. This article is (C) Springer and permission has been granted for this version to appear in e-Publications@Marquette. Springer does not grant permission for this article to be further copied/distributed or hosted elsewhere without the express permission from Springer. 
eliminated by the channel, the results support the idea that horizontal planar arm movements are optimized so as to minimize variance in the combined visuo-proprioceptive limb state estimate. Two other explanations are also viable. Because resolution of sensory conflict may have required cognitive processing beyond that typical in reaching, subjects could have attended exclusively to vision as a most efficient directional control solution (a context-dependent switching strategy; Salinas 2004; cf. Haruno et al., 2001; Wolpert and Kawato 1998). Alternatively, the visual channel altered the task such that motions orthogonal to the intended direction did not impede bringing the cursor to the target, and so optimization of only task-relevant control costs (cf. Todorov and Jordan, 2002) predicts that directional errors should have remained uncorrected. In this case, it is unclear whether the visual channel should have had any impact on multisensory integration.

We adapted psychophysical techniques previously used to examine haptic sensitivity to curvature during prolonged exploration of environmental surfaces (Henriques and Soechting, 2003). Subjects in a primary experiment indicated whether they perceived point-to-point hand trajectories to deviate from a straight-line path during active reaching and passive reach-like movements guided by a robotic device. Subjects were deprived of movement-related visual feedback in some trials whereas cursor motion was constrained to lie within a visual channel in others. Subjects in a control experiment experienced several different environmental loads during movement whereas subjects in second control experiment performed a concurrent and unrelated cognitive loading task designed to characterize the timecourse of interference between tasks. In all cases, only proprioception was informative of actual curvature. Minimum detectible hand path curvature and the range of curvatures over which subjects exhibited uncertainty in response varied considerably across experimental conditions, thus revealing significant context-dependence in the proprioceptive contributions to perception of hand path during goaldirected arm movements. Implications of these perceptual findings on limb state estimation for other sensorimotor behaviors are discussed. Portions of this work have been presented in abstract form (Lillis and Scheidt, 2003).

Experimental Brain Research, Vol. 204, No. 2 (July 2010): pg. 239-254. DOI. This article is ( Springer and permission has been granted for this version to appear in e-Publications@Marquette. Springer does not grant permission for this article to be further copied/distributed or hosted elsewhere without the express permission from Springer. 
NOT THE PUBLISHED VERSION; this is the author's final, peer-reviewed manuscript. The published version may be accessed by following the link in the citation at the bottom of the page.

\section{Methods}

Forty-two right-hand dominant people (20 female, age: 18-40) gave written, informed consent to participate in this study. All procedures were institutionally approved in accord with the 1964 Declaration of Helsinki. No one had known neurological disorders. Subjects grasped the handle of a low-inertia robot with their right hand and attended to hand motion during active (subject driven) and passive (robot driven) movements between two locations in the horizontal workspace (Fig. 1A). The upper arm was supported against gravity ( $\sim 85^{\circ}$ abduction) by a sling attached to a $2.8 \mathrm{~m}$ tall structure. Direct view of the arm, hand and robot was occluded by an opaque, horizontal screen mounted $1 \mathrm{~cm}$ above the robot's handle. A vertical shield blocked view of the shoulder and sling. "Home" and "goal" targets were projected onto the horizontal screen $15 \mathrm{~cm}$ apart so that hand movements were directed away from the body along the line passing through the shoulder center of rotation (the y-axis). All movements were constrained by the robot to follow paths with predefined curvature within the horizontal plane. Subjects were provided two types of visual feedback depending on experimental condition. In the visual channel condition (CHAN), a cursor $(0.5 \mathrm{~cm}$ dia.) provided visual feedback of ongoing motion projected onto the $y-$ axis such that all reaches looked straight (thus establishing a discrepancy between visual and proprioceptive feedback of motion). In the no visual feedback condition (NONE), cursor feedback was removed entirely.

a

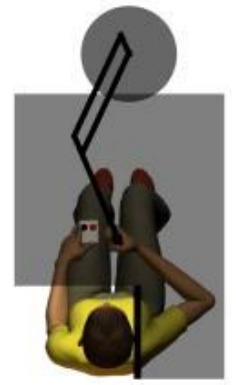

b

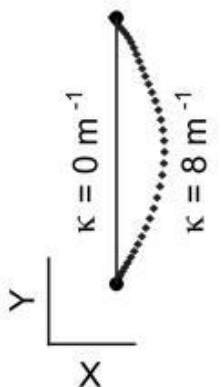

C

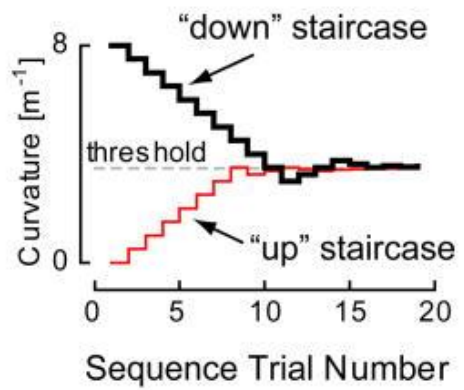

d

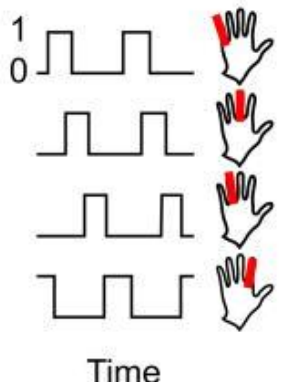

Time

Figure 1 A) Experimental Setup. B) Hand paths showing the range of curvatures tested in this study. Maximum deviations from a straight-line were $\sim 4.5 \mathrm{~cm}$ at the

Experimental Brain Research, Vol. 204, No. 2 (July 2010): pg. 239-254. DOI. This article is C Springer and permission has been granted for this version to appear in e-Publications@Marquette. Springer does not grant permission for this article to be further copied/distributed or hosted elsewhere without the express permission from Springer. 
NOT THE PUBLISHED VERSION; this is the author's final, peer-reviewed manuscript. The published version may be accessed by following the link in the citation at the bottom of the page.

greatest curvatures tested $\left(8 \mathrm{~m}^{-1}\right)$. Horizontal and vertical calibration: $\left.0.05 \mathrm{~m} . \mathrm{C}\right)$ Example of the dual staircase technique as realized for one block of trials. D) Temporal sequence of finger keystrokes used as a secondary task (distractor) in the DUAL task condition of Experiment 3.

The robot was powered by two brushless DC torque motors (M605-A Goldline; Kollmorgen, Inc. Northampton, MA). A 16-bit data acquisition board (PCI-6031E DAQ; National Instruments Inc., Austin, TX) sampled analog force and acceleration data from a load cell (85M35A-I40-A-200N12; JR3 Inc., Woodland, CA) mounted under the handle. Handle location was resolved within $0.038 \mathrm{~mm}$ using joint angular position data from two 17-bit encoders (A25SB17P180C06E1CN; Gurley Instruments Inc., Troy, NY). A stiff PID controller enforced hand trajectories of controlled curvature. Data collection and control were performed at 1000 sample/s.

We recorded electromyograms (EMGs) in a subset of subjects using differential surface electrodes (DE-2.1 electrodes; Bagnolli 8 amplifier; Delsys Inc., Taunton, MA) to confirm compliance with the ACTIVE/PASSIVE task instructions described below. Monitored muscles included the elbow flexor biceps brachii (short head; BIC) and the elbow extensor triceps (lateral head; TRI). EMGs were hardware bandpass filtered from 10 to $450 \mathrm{~Hz}$, amplified ( $\times 1000)$ and sampled (16bit resolution at $1000 \mathrm{~Hz}$ ) prior to off-line storage and analysis. EMGs during isometric maximum voluntary contractions (MVCs) were collected prior to testing to allow estimation of relative muscular effort. The series of MVCs included three each of elbow flexion and extension collected with the hand held at the home position. The peak EMG value for each muscle after signal conditioning (see Data Analysis) was taken as the maximal EMG for that muscle. EMGs recorded from the experimental trials were normalized by these maximal, isometric EMG values: $E M G_{\text {norm }}(t)=E M G(t) / E M G_{\max }$.

\section{Experimental design and predicted results}

Three sets of experiments explored how proprioceptive contributions to the perception of hand-path curvature are influenced by extrinsic, intrinsic and attentional sources of performance variability during horizontal planar arm movements (Table 1). Subjects were to attend to hand motion either while the robot moved their hand passively through paths of predefined curvature or while the subject

Experimental Brain Research, Vol. 204, No. 2 (July 2010): pg. 239-254. DOI. This article is @ Springer and permission has been granted for this version to appear in e-Publications@Marquette. Springer does not grant permission for this article to be further copied/distributed or hosted elsewhere without the express permission from Springer. 
actively reached for the target as the robot forced the hand along similar curved paths. During robot-generated movements (the PASSIVE case), the imposed $y$-axis motion had a bell-shaped speed profile ( $0.7 \mathrm{~s}$ duration) whereas the $\mathrm{x}$-position was constrained to the perimeter of a circle passing through the two targets. The circle's radius $r=1 / \kappa$ determined the curvature $\kappa$, which ranged between 0.0 $\mathrm{m}^{-1}$ (straight) and $8.0 \mathrm{~m}^{-1}$ (unmistakably curved) (Fig. 1B). For subject-generated movements (the ACTIVE case), subjects provided the motive force driving the hand toward the target in the $y$-direction while the robot constrained hand position in the $\mathrm{x}$-direction.

Immediately upon target acquisition, the visual display was blanked and subjects indicated whether or not they felt the movement to be curved either using a two button YES/NO response box (Experiments 1 and 2) or by verbal response (Experiment 3). Subjects were instructed to "Do the best you can using all information available to you." After responding, the robot moved the hand slowly back to the starting point. During this passive return (and only after active movements), subjects were provided visual feedback indicating whether the reach was too fast (< $0.6 \mathrm{~s}$ duration), too slow ( $>0.8 \mathrm{~s}$ ) or just right.

\begin{tabular}{ccccc}
\hline Experiment & Visual condition & Additional bias forces & Movement Type & Tasks \\
\hline Primary & CHAN & NONE & ACTIVE & SINGLE \\
& NONE & & PASSIVE & \\
Control 1 & NONE & +10 N ASSIST & ACTIVE & SINGLE \\
& & 0 N NULL & PASSIVE- & \\
& & -10 N RESIST & & \\
Control 2 & CHAN & NONE & PASSIVE & SINGLE \\
& NONE & & & DUAL \\
\hline
\end{tabular}

Table 1 Experimental conditions

*7 of 11 subjects in Control Experiment 1 were tested on the passive condition

We used a dual-staircase algorithm (Cornsweet, 1962; cf. Scheidt and Kertesz, 1992) to adjust hand path curvature from trial to trial within a block of movements based on the subject's response in previous trials (Fig. 1B). This method maximizes sampling density about the minimum detectable curvature value (the detection threshold). On each trial, a curvature value was randomly selected 
from either an up- or a down-staircase. The down staircase began at $\kappa$ $=8 \mathrm{~m}^{-1}$ and decremented (step size $=-1 \mathrm{~m}^{-1}$ ) until the subject indicated they no longer detected curvature. The staircase then reversed and began incrementing at half the previous step size until another change in response occurred, whereupon the staircase reversed and the step size again halved. Curvature never decremented below $0 \mathrm{~m}^{-1}$ nor above $8 \mathrm{~m}^{-1}$ to avoid the singular condition wherein the diameter of mechanical constraint is less than the distance between beginning and end positions. A similar algorithm was implemented for the up staircase, which began at $\kappa=0$ and an initial step size $=+1 \mathrm{~m}^{-1}$. A trial block was complete when both staircases reversed at least five times, which typically required $\sim 40$ trials and $\sim 10$ minutes. Subjects performed 3 trial blocks for each experimental condition described below.

Pilot studies found that detection thresholds obtained using the dual staircase method reported here were statistically indistinguishable from thresholds obtained using a two-alternative forced choice "method of constant stimuli" approach described by Gescheider (1997). This second approach quantifies response bias (a predisposition toward one or the other response options when in fact the subject is merely guessing), but more than quadruples the requisite number of movements per threshold evaluation, thus resulting in excessively long experimental sessions ( $>5 \mathrm{hr}$ ). Our pilot data yielded no evidence for task-dependent response bias in subjects performing our task and so we reasoned that it would be acceptable to forego such information in favor of the staircase approach and shorter experimental sessions. Moreover, the impact of non-stationary response bias on our findings is minimal because treatment block order was randomized within subject and counterbalanced across subjects and because we only compared curvature detection thresholds across experimental treatments within subjects.

Primary Experiment Twenty subjects performed three blocks each of four trial types exploring how proprioceptive contributions to limb state estimation are influenced by task-relevant motor activity and the presence of visual feedback with minimal task-relevant variability. We tested all permutations of movement type (PASSIVE or ACTIVE) and visual feedback type (NONE or CHAN). Block order was randomized and counterbalanced across subjects. We predict that if proprioceptive

Experimental Brain Research, Vol. 204, No. 2 (July 2010): pg. 239-254. DOI. This article is (C Springer and permission has been granted for this version to appear in e-Publications@Marquette. Springer does not grant permission for this article to be further copied/distributed or hosted elsewhere without the express permission from Springer. 
feedback is attenuated by central events related to the planning and execution of reaching (cf. Williams and Chapman, 2000; Ghez and Pisa, 1972; Kakuda and Nagaoka, 1998) or compromised by motor noise (Hamilton et al 2004, Jones 2002), curvature detection capabilities in passive movements should surpass those in active trials. Alternatively, if efference copy and an internal model supplement sensory feedback in estimating limb state (Miall et al. 1993; Wolpert et al, 1995a), detection capabilities in active trials should surpass those in passive trials. If proprioception is discounted when the variability of visual feedback is artificially minimized (cf. Scheidt et al., 2005) as predicted by maximum likelihood estimator models of sensory integration (Beers et al. 1999; Ernst and Banks, 2002; Koerding and Wolpert, 2004), detection performance should be compromised in CHAN relative to NONE trials. However, if subjects attend only to visual feedback during CHAN trials, then CHAN condition thresholds should encroach on the maximum tested value $\left(8 \mathrm{~m}^{-1}\right)$.

Control Experiment 1 Eleven subjects performed three blocks each of three types of active arm movements to explore how kinetic task demands influence proprioceptive detection of hand path curvature. The three movement types differed in the amount of steady-state bias force generated by the robot along the $+y$-axis: $+10 \mathrm{~N},-10 \mathrm{~N}$, or $0 \mathrm{~N}$ (the NULL load) (see also Wolpert et al, 1995a). Non-zero bias forces either ASSISTed $(+10 \mathrm{~N})$ or RESISTed $(-10 \mathrm{~N})$ motion. Bias forces were applied after the hand was robotically transported to the home target. The subject stabilized the hand at that position with veridical cursor feedback for $1.0 \mathrm{~s}$. The cursor then disappeared and the goal target appeared cueing an ACTIVE movement. Bias forces were eliminated gradually (i.e. over a $250 \mathrm{~ms}$ interval) once the hand acquired the goal. As in Exp 1, curvature constraints were imposed during the reach. Subjects were presented with no visual feedback of hand position or trajectory during or after movement. Seven subjects performed additional PASSIVE blocks of trials to obtain comparison EMG data for this condition. Block presentation order was randomized and counterbalanced across subjects.

Because information from both shoulder and elbow joints is necessary to determine whether hand paths are straight, and because lengthening muscles contribute importantly to proprioceptive sense of movement (cf. Capaday and Cooke, 1981), we would predict an 
increase in curvature detection threshold in just the ASSIST condition if the effect were due to reduced spindle fidelity resulting from signaldependent motor noise. This is because opposition of the $+10 \mathrm{~N}$ ASSIST bias force requires significant activation of elbow flexor BIC (which lengthens throughout the elbow extension movement studied here) whereas opposition of the -10 N RESIST and NULL bias forces mainly require activation of elbow extensor TRI (which shortens). In contrast, we would predict an equal increase in threshold in all active conditions if proprioceptive feedback were inhibited generally during movement due to central phenomena related to the planning and execution of movements (Voss et al, 2006, 2008; Williams and Chapman 2000; Ghez and Pisa, 1972; Seki et al., 2003). Finally, we would predict a change in threshold in only the ASSIST and RESIST conditions if increased afferent feedback from cutaneous sources and tendon organ receptors modulates muscle spindle sensitivity (cf. Chapman et al., 1987), as also suggested by studies of reflex modulation in gait (cf. Nielsen, 2004).

Control Experiment 2 Eleven subjects performed three blocks each of four trial types exploring the interaction between visual and proprioceptive feedback and the consequence of varying attentional demands during movement. Experimental treatments included all permutations of visual feedback type (NONE or CHAN) and the presence/absence of a secondary distractor task (DUAL or SINGLE). In each case, the robot moved the subject's dominant hand passively through paths of controlled curvature. In the SINGLE condition, subjects simply performed the passive curvature detection task described in the primary experiment. In DUAL trials, subjects also performed a continuous repetitive sequence of keyboarding movements using four fingers on the non-dominant hand (little finger $>$ middle $->$ ring -> index) (Fig 1D). This was to be done as accurately and as fluently as possible, with key presses performed in time with a metronome (120 beats per minute). Subjects practiced the secondary task before experimentation until comfortable. The secondary task was to be performed throughout the entire testing block asynchronous to the detection task. This facilitated assessment of the time-course of interference between tasks. Custom hardware recorded key press timing and mapped presses onto distinct audible tones that were used to assess accuracy and fluency. Subjects were encouraged to perform better whenever they made sequence errors. Five subjects from whom

Experimental Brain Research, Vol. 204, No. 2 (July 2010): pg. 239-254. DOI. This article is @ Springer and permission has been granted for this version to appear in e-Publications@Marquette. Springer does not grant permission for this article to be further copied/distributed or hosted elsewhere without the express permission from Springer. 
EMG recordings were collected also performed a block of active movements without visual feedback to facilitate comparison of relative muscle activity in the passive trial blocks. Block presentation order was randomized and counterbalanced across subjects.

If dividing attention increases sensitivity of Ia spindles as suggested by microneurographic studies in relaxed humans (RibotCiscar et al., 2000), DUAL task sensitivity to curvature should exceed SINGLE task sensitivity regardless of visual feedback condition. If, rather, the most important effect of dividing attention is to increase the variability of Ia spindle spike trains (also shown by Ribot-Ciscar et al., 2000), then optimization of multisensory integration (cf. Ghahramani, 1995) predicts that the converse trend should be observed. If division of attention only interferes with complex secondary processes transforming perception into action, we expect a DUAL task increase in the variability of the subjects' responses but no effect on curvature detection sensitivity. A similar sized decrease in curvature detection performance in all cases involving either CHAN or DUAL conditions would suggest that resolution of sensory discordance and contralateral sequencing compete for a common, limited, attentional resource (cf. Bonnel and Hafter, 1998; Driver and Spence 1998).

\section{Data Analysis}

Hand paths were low-pass filtered using a second order Butterworth filter with $20 \mathrm{~Hz}$ cutoff prior to computing hand velocities. An identical filter was applied to velocities before computing accelerations. We identified kinematic and kinetic movement features using an automated algorithm within the MATLAB computing environment (Mathworks, Inc., Natick, MA). Trials were aligned by movement onset $t_{0}$ (i.e. when hand speed first exceeded $0.05 \mathrm{~m} / \mathrm{s}$ ). Movement termination $t_{t}$ was when hand speed last exceeded 0.05 $\mathrm{m} / \mathrm{s}$. Each of the following features was verified visually and adjusted manually if necessary: the time $t_{s}$ and magnitude of peak hand speed, the time $t_{a}$ and magnitude of peak acceleration (within the interval $t_{0}$ and $t_{s}$ ) and hand force magnitude in the $x-y$ plane at $t_{0}$. Movement duration was the interval between $t_{0}$ and $t_{t}$. Post-processing of EMGs included band-pass filtering from $30-300 \mathrm{~Hz}$ (4 $4^{\text {th }}$-order Butterworth) followed by full-wave rectification and low pass filtering at $20 \mathrm{~Hz}$ ( $4^{\text {th }}$ -

Experimental Brain Research, Vol. 204, No. 2 (July 2010): pg. 239-254. DOI. This article is @ Springer and permission has been granted for this version to appear in e-Publications@Marquette. Springer does not grant permission for this article to be further copied/distributed or hosted elsewhere without the express permission from Springer. 
order Butterworth). For visualization purposes, the kinematic, kinetic and EMG time series were aligned by movement onset and averaged across trials within condition and subject.

Each trial block produced a set of data pairs $\left\{\kappa_{i}, \phi_{i}\right\}$ where $\kappa_{i}$ is the curvature experienced on trial $i$ and $\phi_{i}$ is the subject's decision whether the trajectory was curved $(\phi=1)$ or not $(\phi=0)$. A sigmoidal likelihood function (Eqn 1) was fit to the $\left\{\kappa_{i} \phi_{i}\right\}$ data pooled across trial blocks within experimental condition for each subject:

$$
\operatorname{Pr}\left(\phi_{\kappa}\right)=\frac{e^{\alpha+\beta * \kappa}}{1+e^{\alpha+\beta * \kappa}} .
$$

$\alpha$ and $\beta$ define the shape of this psychometric function, which we use to identify a pair of secondary performance measures. Curvature detection threshold $\left(\kappa_{t}\right)$ was defined as the value at which the function passed through 0.5 (i.e. where subjects would respond with equal probability that a trajectory was curved or straight). Response Uncertainty (RU) quantifies indecision in response selection and was defined as the range of curvatures over which the subject demonstrated variable responses and was estimated as the difference in curvatures yielding likelihoods of $25 \%$ and $75 \%$. RU values are low when the slope of the psychometric function is steep whereas RU is high when the slope is shallow. As shown in the Appendix, the ratio of thresholds obtained in two experimental conditions reflects the subjective change in proprioceptive uncertainty $\left(\% \Delta \sigma_{\text {prop}}\right)$ caused by one treatment relative to the other. In contrast, $\mathrm{RU}$ is a complex psychological construct likely to include other high-level noises (Kontsevich and Tyler, 1999) distinct from those inducing changes in the subject's implicit evaluation of proprioceptive uncertainty.

We evaluated distractor task performance by computing the likelihood of keystroke events within each $50 \mathrm{~ms}$ bin spanning the interval $\{-500 \mathrm{~ms},+1500 \mathrm{~ms}\}$ bounding movement onset. The likelihood was calculated for each subject within each trial block by dividing the keystroke bin counts (accumulated across all trials) by the number of keystrokes within that block. We computed sequence error rate by dividing the number of errors in each bin by the keystroke bin

Experimental Brain Research, Vol. 204, No. 2 (July 2010): pg. 239-254. DOI. This article is (C Springer and permission has been granted for this version to appear in e-Publications@Marquette. Springer does not grant permission for this article to be further copied/distributed or hosted elsewhere without the express permission from Springer. 
count. These raw error rates were then normalized by dividing by the overall sum of the individual bin rates to yield a measure of error event likelihood.

Statistical testing was performed using Minitab software (Minitab, Inc., State College, PA) to examine the impact of extrinsic, intrinsic and attentional sources of performance variability on the perception of hand path kinematics during reaching. General linear model repeated measures ANOVA were used to account for subjectdependent bias in $\% \Delta \sigma_{\text {prop }}$ and RU when comparing these measures across experimental conditions. Tukey t-tests accounted for multiple comparisons. Effects were considered significant at $a=0.05$. Data values are reported as mean \pm 1 SD. Figure error bars represent $95 \%$ confidence intervals of the mean.

\section{Results}

Hand movements terminated within the goal and had smooth, unimodal speed profiles in all experiments (Figs 2A, ,3A3A and and4A;4A; top). Across subjects, movement durations averaged $0.68 \mathrm{~s}$ to $0.70 \mathrm{~s}$ for each condition in each experiment, well within the desired range $(0.6 \mathrm{~s}$ to $0.8 \mathrm{~s}$ ). Peak hand speed did not differ between conditions except in the primary experiment, where active movements were slightly faster than passive movements (peak speeds of $0.38 \pm$ $0.05 \mathrm{~m} / \mathrm{s}$ vs. $0.35 \pm 0.002 \mathrm{~m} / \mathrm{s}$, respectively). This difference (less than $10 \%$ ) was accentuated by the great regularity of robotically imposed movements. Because the full range of curvature values was presented in each trial block, this subtle difference in speed was unlikely of functional significance or able to explain differences in the curvature detection threshold and uncertainty we describe. 
NOT THE PUBLISHED VERSION; this is the author's final, peer-reviewed manuscript. The published version may be accessed by following the link in the citation at the bottom of the page.
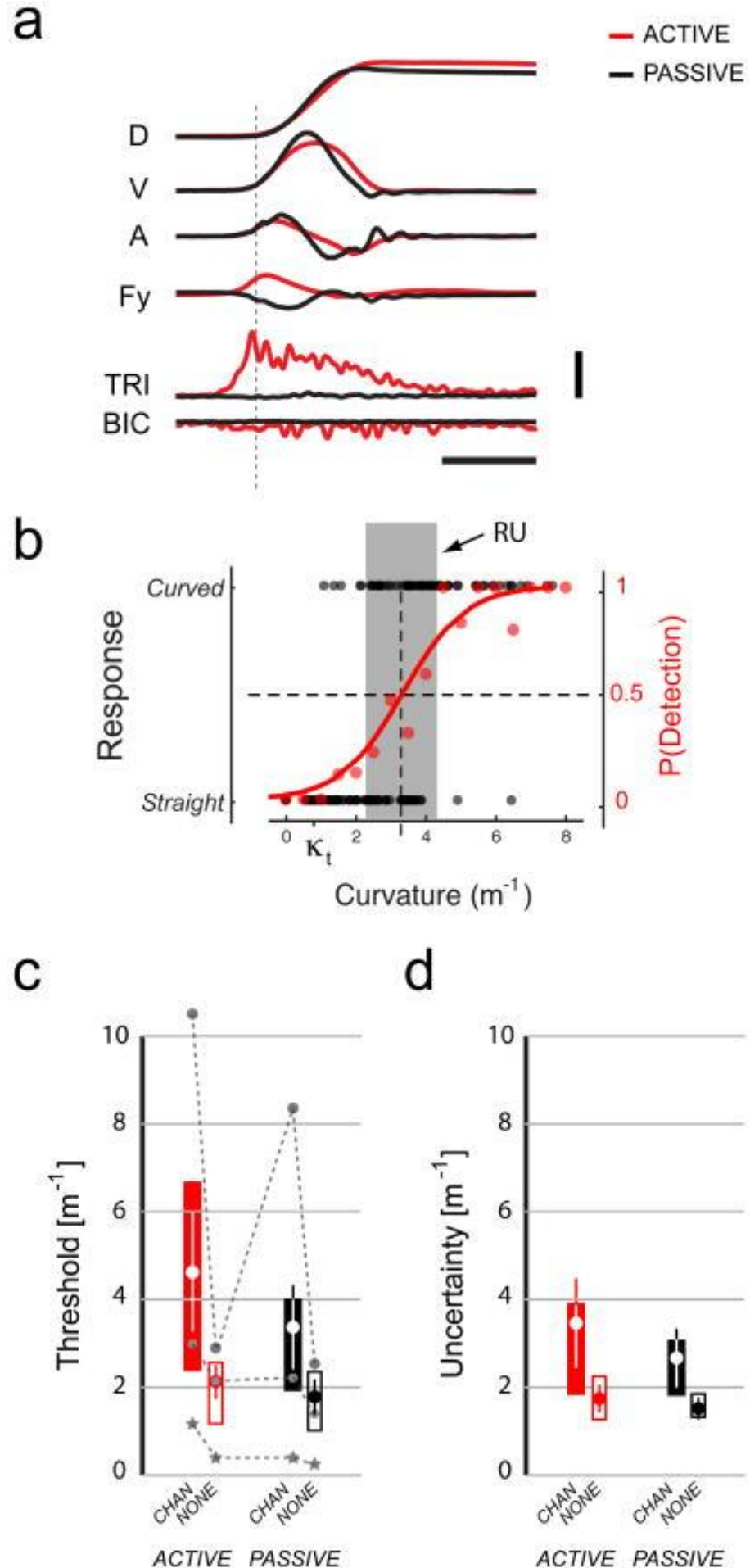

Figure 2 Results of Primary Experiment. A) Average hand displacements (D), tangential velocities $(V)$, accelerations $(A)$, subject-generated $Y$-axis hand forces $\left(F_{y}\right)$ and EMG activities in the triceps (TRI) and biceps (BIC) for active (red) and passive

Experimental Brain Research, Vol. 204, No. 2 (July 2010): pg. 239-254. DOI. This article is (C) Springer and permission has been granted for this version to appear in e-Publications@Marquette. Springer does not grant permission for this article to be further copied/distributed or hosted elsewhere without the express permission from Springer. 
NOT THE PUBLISHED VERSION; this is the author's final, peer-reviewed manuscript. The published version may be accessed by following the link in the citation at the bottom of the page.

(black) trials in a representative subject. Horizontal calibration: $500 \mathrm{~ms}$. Vertical calibration: D: $0.1 \mathrm{~m}$; V: $0.2 \mathrm{~m} / \mathrm{s} ; A: 4 \mathrm{~m} / \mathrm{s}^{2}$; Fy: $20 \mathrm{~N}$; EMGs: $5 \%$ MVC. The dotted vertical line indicates movement onset. B) Best-fit psychometric function (red) for a representative experimental condition in one subject. Black dots correspond to individual movement hand path assessments. The curvature detection threshold $\mathrm{k}_{\mathrm{t}}$ was estimated as the value at which the fitted psychometric function passed through $P($ Detection $)=0.5$. The red dots correspond to the probability of "curved" response computed within narrow $\left(0.5 \mathrm{~m}^{-1}\right.$ wide) curvature bins. Response Uncertainty (RU, width of the gray band) yields an estimate of the subject's sensitivity to small changes in curvature around $\mathrm{K}_{\mathrm{t}}$. See text for details. C) Average curvature detection thresholds (large•) for all four combinations of movement type (ACTIVE: red; PASSIVE: black) and visual feedback type (CHAN: solid; NONE: open bars) in this experiment. Boxes correspond to the ranges spanned by the first and third quartiles of the dataset. Error bars indicate the $95 \% \mathrm{CI}$ of the mean. The gray connected symbols indicate threshold values obtained from three selected individuals with very different mean values. D) Average Response Uncertainties as in panel C.

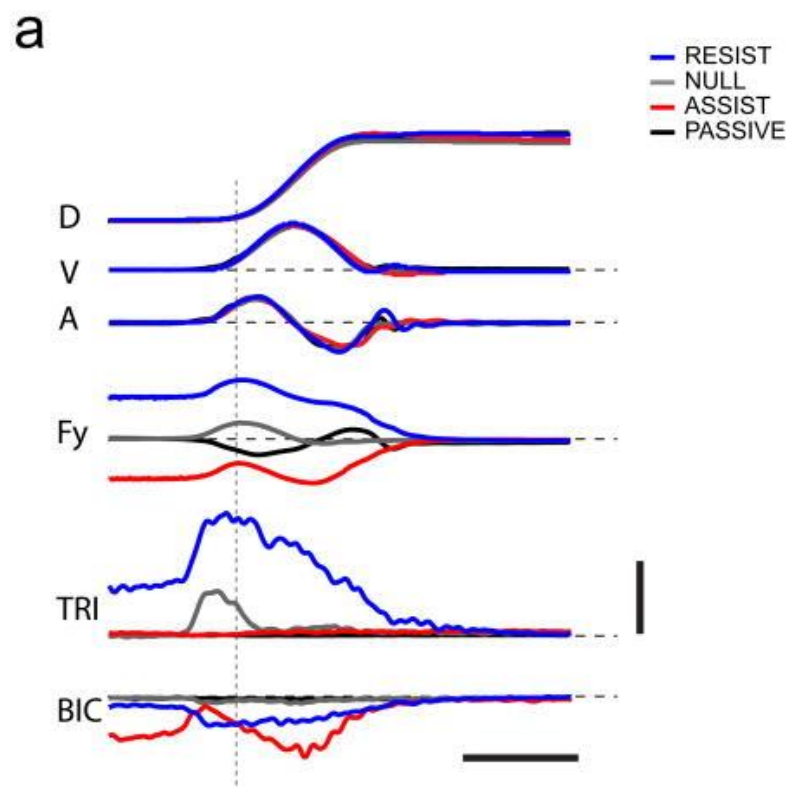

b

C
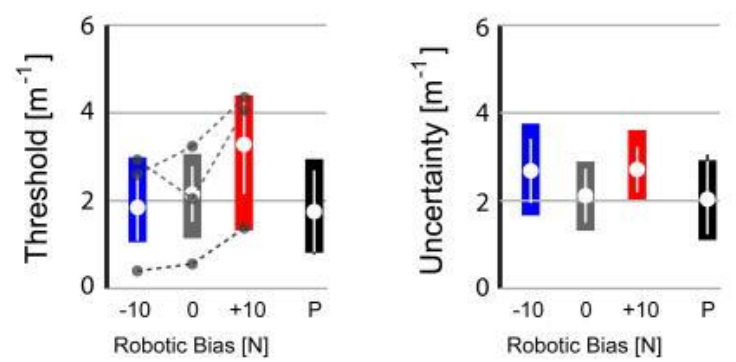

Experimental Brain Research, Vol. 204, No. 2 (July 2010): pg. 239-254. DOI. This article is (C) Springer and permission has been granted for this version to appear in e-Publications@Marquette. Springer does not grant permission for this article to be further copied/distributed or hosted elsewhere without the express permission from Springer. 
NOT THE PUBLISHED VERSION; this is the author's final, peer-reviewed manuscript. The published version may be accessed by following the link in the citation at the bottom of the page.

Figure 3 Results of Control Experiment 1. A) Average hand displacements (D), tangential velocities $(V)$, accelerations $(A)$, subject-generated $Y$-axis hand forces $\left(F_{y}\right)$ and EMG activities in the triceps (TRI) and biceps (BIC) for robotic assistive $+10 \mathrm{~N}$ bias force trials (red), resistive $-10 \mathrm{~N}$ trials (blue) no bias force trials $(0 \mathrm{~N}$; gray) and passive trials (black) in a representative subject. Horizontal calibration: $500 \mathrm{~ms}$. Vertical calibration: D: $0.1 \mathrm{~m}$; V: $0.2 \mathrm{~m} / \mathrm{s} ; A: 4 \mathrm{~m} / \mathrm{s}^{2} ; F_{y}: 20 \mathrm{~N}$; EMGs: $5 \%$ MVC. The dotted vertical line indicates movement onset. B) Average curvature detection thresholds (large•) for all trial types tested in this experiment. Boxes correspond to the ranges spanned by the first and third quartiles and the entire dataset. Error bars indicate the $95 \% \mathrm{CI}$ of the mean. The gray connected symbols indicate threshold values obtained from three selected individuals. C) Average Response Uncertainties as in panel $\mathrm{B}$.

a

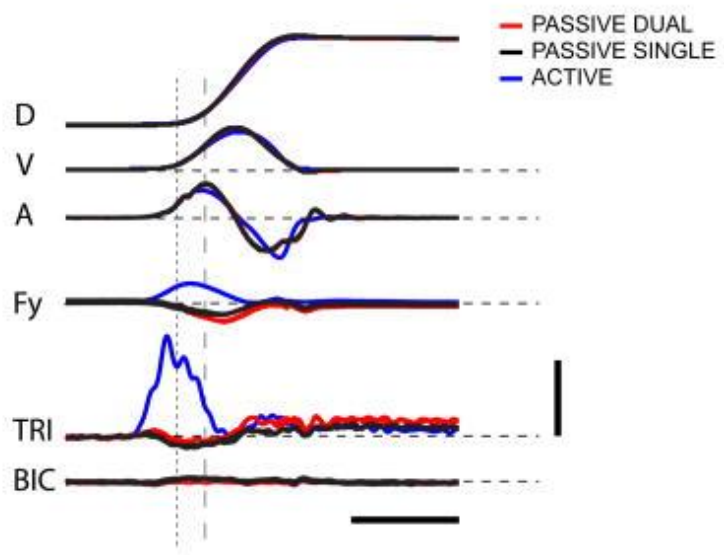

b

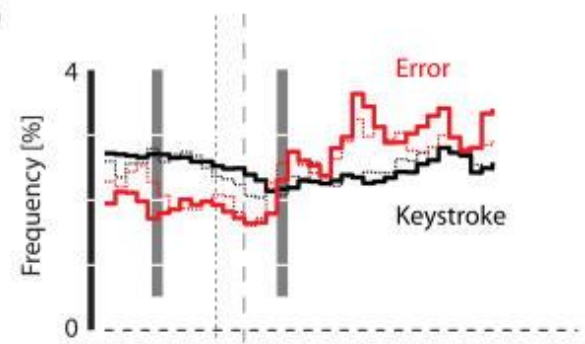

C
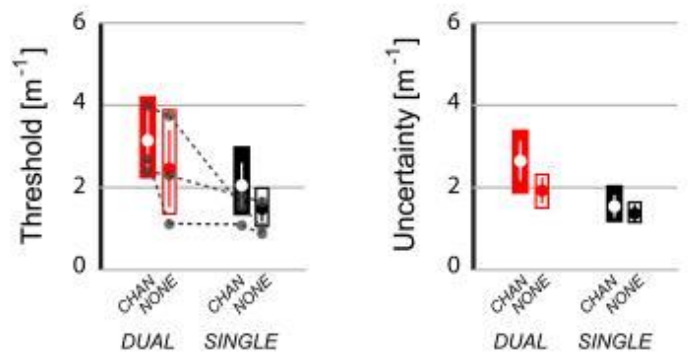

Experimental Brain Research, Vol. 204, No. 2 (July 2010): pg. 239-254. DOI. This article is (C Springer and permission has been granted for this version to appear in e-Publications@Marquette. Springer does not grant permission for this article to be further copied/distributed or hosted elsewhere without the express permission from Springer. 
NOT THE PUBLISHED VERSION; this is the author's final, peer-reviewed manuscript. The published version may be accessed by following the link in the citation at the bottom of the page.

Figure 4 Results of Control Experiment 2. A) Average hand displacements (D), tangential velocities $(V)$, accelerations $(A)$, subject-generated $Y$-axis hand forces $\left(F_{y}\right)$ and EMG activities in the triceps (TRI) and biceps (BIC) for passive trials performed under SINGLE (black) and DUAL (red) task conditions in a representative subject. Average traces for active (subject-generated) movements are also shown in blue for this subject. Horizontal calibration: $500 \mathrm{~ms}$. Vertical calibration: D: $0.1 \mathrm{~m} ; \mathrm{V}: 0.2 \mathrm{~m} / \mathrm{s}$; A: $4 \mathrm{~m} / \mathrm{s}^{2} ; F_{y}: 20 \mathrm{~N}$; EMGs: 5\% MVC. The dotted vertical line indicates movement onset. The dashed vertical line indicates the time of peak acceleration. B) Frequency of distractor task keystroke (black) and error events (red) as a function of time relative to movement onset (dotted vertical line). Bin width $=50 \mathrm{~ms}$. An individual subject's data is shown as thin dotted lines, and were compiled from the same subject whose movement data are shown in panel $A$, using the same time scale. Across-subject average values are shown as thick traces. C) Average curvature detection thresholds (large•) for all four combinations of task type (DUAL/SINGLE) and visual feedback type (CHAN/NONE) in this Experiment. Boxes correspond to the ranges spanned by the first and third quartiles and the entire dataset. Error bars indicate the $95 \% \mathrm{CI}$ of the mean. The gray connected symbols indicate threshold values obtained from three selected individuals. D) Average Response Uncertainties as in panel C.

\section{Primary Experiment}

As shown for a representative subject, hand forces during active movements were directed opposite those during passive trials (red vs. black traces) (Fig 2A; bottom). Active movement required modest activation of the elbow extensor TRI and flexor BIC whereas passive movements elicited little activity in either muscle. These patterns were characteristic of all four subjects from whom EMGs were collected. Figure 2B shows the psychometric function of Eq. 1 (red line) fit to the individual trial response data (black dots) for a representative trial block in one subject. Eq. 1 provides a good fit to the response probability computed within narrow $\left(0.5 \mathrm{~m}^{-1}\right.$ wide) curvature bins (red dots). All 20 subjects indicated that hand trajectories were straight when curvature values were low and movements to be curved when curvature was at its maximum value $\left(8 \mathrm{~m}^{-1}\right)$. Every subject had a range of curvature values over which their responses demonstrated uncertainty (RU gray band in Fig 2B). We observed considerable subject-dependent bias both in detection threshold (shown for three selected subjects in Fig 2C) and RU (individual data not shown). We used a two-way, repeated measures ANOVA to account for subjectdependent differences in mean performance and found that movement type (ACTIVE vs. PASSIVE: $F_{(1,57)}=5.66 ; p=0.021$ ) and visual feedback type (CHAN vs. NONE: $\left.F_{(1,57)}=36.86 ; p<0.0005\right)$ influenced

Experimental Brain Research, Vol. 204, No. 2 (July 2010): pg. 239-254. DOI. This article is (C Springer and permission has been granted for this version to appear in e-Publications@Marquette. Springer does not grant permission for this article to be further copied/distributed or hosted elsewhere without the express permission from Springer. 
curvature detection thresholds significantly. No interaction between the factors was found $\left(F_{(1,57)}=1.83 ; p=0.181\right)$.

Curvature detection thresholds were $42 \pm 55 \%$ higher in active movements $\left(\kappa_{\mathrm{t}}=3.23 \pm 2.53 \mathrm{~m}^{-1}\right)$ than in the passive case $\left(2.43 \pm 1.81 \mathrm{~m}^{-1}\right)$ (ratios computed on a per-subject basis prior to computing summary statistics). Therefore, proprioceptive uncertainty increased in active relative to passive movements (i.e. $\% \Delta \sigma_{\text {prop }}=$ $42 \pm 55 \%)$. Thresholds were higher in trials performed with CHAN feedback than in trials performed without ongoing visual feedback $\left(\kappa_{\mathrm{t}}=3.85 \pm 2.66 \mathrm{~m}^{-1}\right.$ vs. $\left.1.81 \pm 0.89 \mathrm{~m}^{-1} ; \% \Delta \sigma_{\text {prop }}=151 \pm 198 \%\right)$ (Fig $2 \mathrm{C})$ : minimizing trial-to-trial variability in visual feedback also reduced the influence of proprioception on the subject's internal estimate of limb state. Thresholds in the CHAN condition consistently encroached on the upper bound of curvature in only two of twenty subjects, providing little support for the idea that visual feedback was used to the exclusion of proprioception in the conscious evaluation of reach kinematics. Repeating the ANOVA after removing these subjects yielded similar results leading to identical conclusions.

A separate two-way, repeated measures ANOVA revealed systematic variation in Response Uncertainty with visual feedback type $\left(F_{(1,57)}=22.48 ; p<0.0005\right)$ but not movement type $\left(F_{(1,57)}=2.14\right.$; $\mathrm{p}=0.149$ ) (Fig 2D). No interaction between the two factors was observed $\left(F_{(1,57)}=0.67 ; p<0.417\right)$. RU was greater in the CHAN condition than when visual feedback was eliminated entirely (2.99 \pm $1.69 \mathrm{~m}^{-1}$ vs. $1.66 \pm 0.54 \mathrm{~m}^{-1}$, respectively) and thus, subjects were less decisive in curvature evaluation when conflict between visual and proprioceptive feedback was introduced. Because active movements did not also lead to increased indecision, the two experimental factors impacted perception in dissimilar ways.

\section{Control Experiment 1}

As shown for a representative individual, subjects readily stabilized the hand at the home position against the different bias forces (Fig 3A). Hand force varied only modestly across time during static stabilization; the standard deviation of instantaneous force was less than $1.75 \mathrm{~N}$ in each case for each subject. The across-subject average hand force measured at $\mathrm{t}_{0}$ was $-12.5 \pm 3.4 \mathrm{~N},-0.5 \pm 1.0 \mathrm{~N}$ and

Experimental Brain Research, Vol. 204, No. 2 (July 2010): pg. 239-254. DOI. This article is ( Springer and permission has been granted for this version to appear in e-Publications@Marquette. Springer does not grant permission for this article to be further copied/distributed or hosted elsewhere without the express permission from Springer. 
$11.9 \pm 1.2 \mathrm{~N}$ in the $-10 \mathrm{~N}$ RESIST, $0 \mathrm{~N} \mathrm{NULL}$ and $+10 \mathrm{~N}$ ASSIST conditions, respectively. When the bias force opposed movement (Fig 3 , blue), TRI was activated both to overcome the load and to accelerate the hand toward the target. BIC activity increased modestly after TRI activity increased. During active reaching without bias force (Fig 3, gray), much less TRI activity was required to accelerate the hand toward the target and BIC activity was present, but very modest (typically $<3 \% \mathrm{MVC}$ ). When the bias force assisted movement (Fig 3, red), BIC was activated to stabilize the hand at the home target, and movement was initiated by a reduction in BIC activity rather than by a phasic increase in TRI activity. EMG activity in both muscles was minimal during passive, robotically-driven movements (Fig 3, black). Similar activation patterns were observed in all subjects from whom EMGs were collected. We found no difference in peak movement extent, speed or acceleration across conditions, and therefore feedback of peak speed was effective in promoting consistency across all active movement trial blocks.

Again we observed subject-dependent bias (Fig 3B, connected symbols). Detection threshold varied by trial condition (repeated measures ANOVA: $\left.F_{(3,26)}=7.17, p=0.002\right)$ (Fig 3B). Relative to the 0 $\mathrm{N}$ case $\left(\mathrm{K}_{\mathrm{t}}=2.2 \pm 1.0 \mathrm{~m}^{-1} ;\right.$ Fig $3 \mathrm{~B}$, gray $)$, thresholds increased $79 \% \pm 72 \%$ in the robotic $+10 \mathrm{~N}$ ASSIST condition $\left(\mathrm{K}_{\mathrm{t}}=3.3 \pm 1.9 \mathrm{~m}^{-1}\right.$; Fig $3 B$, red), whereas there was no systematic increase or decrease in the $-10 \mathrm{~N}$ RESIST condition ( $\mathrm{K}_{\mathrm{t}}=1.8 \pm 1.2 \mathrm{~m}^{-1}$; Fig 3B, blue).

Thresholds in the $0 \mathrm{~N}$ active condition were modestly higher than those in the passive case for control subjects $\left(\mathrm{K}_{\mathrm{t}}=1.8 \pm 1.1 \mathrm{~m}^{-1}\right.$; Fig 3B, black), consistent with the findings of the primary experiment. Response Uncertainty did not vary systematically by trial type (a separate repeated measures ANOVA: $\mathrm{F}_{(3,26)}=1.77, \mathrm{p}=0.182$ ) (Fig 3C; grand average $\mathrm{RU}=2.55 \pm 1.12 \mathrm{~m}^{-1}$ ).

\section{Control Experiment 2}

As shown for a representative subject, movement kinematics were dictated by the robot and were virtually identical in all the passive conditions examined (Fig 4A, red and black traces). TRI activity peaked at $\sim 5 \% \mathrm{MVC}$ on control block trials requiring subjects to provide motive force (Fig $4 \mathrm{~A}$, blue trace). Passive motion of the 
hand induced minimal EMG in BIC and TRI. These patterns were characteristic of all five subjects from whom EMGs were collected.

The keyboarding and curvature detection tasks mutually interfered with one another in all but one subject (a piano player of sixteen years, who was excluded from further analysis). Distractor task performance in DUAL trial blocks was negatively impacted by curvature detection throughout and after arm movement. The initial likelihood of a keystroke event $\left(2.76 \% \pm 0.21 \%\right.$ at $\left.\mathrm{t}_{0}-300 \mathrm{~ms}\right)$ (Fig 4B, black) began to decline at the onset of movement and reached a minimum shortly before target acquisition $\left(2.13 \% \pm 0.36 \%\right.$ at $\mathrm{t}_{0}+300$ ms) (Fig 4B, gray time windows). Sequence error rates were relatively low around time of peak acceleration $\left(1.60 \% \pm 0.24 \%\right.$ at $t_{0}+150 \mathrm{~ms}$ ) and increased to a peak value near the time of target acquisition $\left(3.24 \% \pm 0.44 \%\right.$ at $t_{0}+650 \mathrm{~ms}$ ) (Fig 4B, red). Error rates remained high to the end of the $2.0 \mathrm{~s}$ data collection period, during which time the subject made a decision and communicated it to the investigator.

Again, subject-dependent bias contributed to the data set variability (thresholds for three selected subjects are shown in Fig 4C). Curvature detection was influenced both by the distractor task (twoway repeated measures ANOVA: $\left.F_{(1,27)}=9.81, p=0.004\right)$ and by visual feedback type $\left(F_{(1,27)}=7.80, p=0.005\right)$ (Fig $4 C$, open bars). There was no interaction between the two factors $\left(F_{(1,27)}=0.01, p=0.943\right)$. Thresholds in the DUAL case $\left(K_{t}=2.82 \pm 1.32 \mathrm{~m}^{-1}\right)$ exceeded those in the SINGLE case $\left(\mathrm{K}_{\mathrm{t}}=2.23 \pm 1.26 \mathrm{~m}^{-1}\right)$ by $42 \pm 56 \%$. Thresholds in the CHAN feedback condition $\left(\mathrm{K}_{\mathrm{t}}=2.83 \pm 1.32 \mathrm{~m}^{-1}\right)$ exceeded those observed in NONE condition $\left(\mathrm{K}_{\mathrm{t}}=2.21 \pm 1.25 \mathrm{~m}^{-1}\right)$ by $37 \pm 29 \%$. The finding of simple main effects for the distractor task and visual feedback condition implies that the effects of the two factors are cumulative (not saturating) in the sense that each treatment leads to a similar change in psychophysical performance and that the combined effect is larger than either effect alone (Fig 4C). Response Uncertainty increased significantly with the introduction of the distractor task (twoway repeated measures ANOVA: $\mathrm{F}_{(1,27)}=22.72, \mathrm{p}<0.0005$; Dual: $2.34 \pm 0.75 \mathrm{~m}^{-1}$, Single: $1.46 \pm 0.41 \mathrm{~m}^{-1}$ ) as well as with the introduction of CHAN feedback (CHAN: $2.10 \pm 0.85 \mathrm{~m}^{-1}$ vs. NONE: $1.63 \pm 0.47 \mathrm{~m}^{-1} ; F_{(1,27)}=4.58, p=0.042$ ) (Fig 4D). Again, only simple main effects were observed (no interaction between factors: $\left.F_{(1,27)}=2.73, p=0.111\right)$. 
NOT THE PUBLISHED VERSION; this is the author's final, peer-reviewed manuscript. The published version may be accessed by following the link in the citation at the bottom of the page.

\section{Discussion}

This study found that proprioceptive contributions to perception of hand path curvature are highly context-sensitive during reaching, being modulated by factors that degrade the integrity of muscle spindle transduction in the motor periphery as well as by factors that influence the central integration of multisensory information. Specifically, the primary and first control experiments found that in reaching, proprioceptive contributions to limb state estimation are sensitive to limb loading in a way consistent with the corruption of muscle spindle afference by efferent motor noise (Cordo et al 1996). The primary experiment also found that minimization of task-relevant variability in the visual feedback reduces the relative importance of proprioception in limb state estimation during movement, supporting the idea that multimodal sensory information is combined so as to minimize uncertainty in the overall perceived limb state (Ghahramani 1995). The second control experiment found the effects of dualtasking and the visual channel to be cumulative - not saturating - and that each treatment alone leads to similar reductions in proprioceptive contributions to limb state estimation during goal-directed reaching.

\section{Motor influences on proprioceptive uncertainty}

Rectilinearity of hand path depends on the amplitude and timing of motion at both the shoulder and elbow (Sainburg et al., 1995; Scheidt and Rymer, 2000). Without vision, the brain must integrate proprioceptive information from both joints to assess whether hand movements are straight. In the primary experiments, curvature thresholds increased $42 \%$ when subjects actively moved the limb as opposed to when the robot moved it. As developed in the Appendix (Eq. A2), this corresponds to a $42 \%$ change in proprioceptive uncertainty caused by active movement. This trend is opposite that expected if efference copy and a forward model were to augment proprioception in the perception of limb state (Wolpert et al., 1995a; Miall et al., 1993; cf. Gritsenko et al., 2007). Any contribution of efference copy to limb state estimation must therefore have been dominated by other factors in our experiments.

The ACTIVE/PASSIVE contrast effect in the primary experiment was not likely due to a general inhibition of proprioceptive input

Experimental Brain Research, Vol. 204, No. 2 (July 2010): pg. 239-254. DOI. This article is (C) Springer and permission has been granted for this version to appear in e-Publications@Marquette. Springer does not grant permission for this article to be further copied/distributed or hosted elsewhere without the express permission from Springer. 
related to central planning and/or execution of active movement (cf. Voss et al., 2006, 2008; Ghez and Pisa, 1972; Soso and Fetz, 1980; Williams and Chapman 2000; Hultborn, 2001; Seki et al., 2003). This is because we observed a dramatic asymmetry of effect in the first control experiment, which required active generation of movement against three different environmental bias forces. Although subjects typically activate the elbow flexor BIC a modest amount in active, unloaded elbow extension movements (cf. Figs 2A and and3A),3A), thresholds increased an additional $79 \%$ when the environment required significant activation of lengthening muscle (the ASSIST case). Because a similar increase was not found when the task required strong activation of shortening muscles (the RESIST case), the increase in proprioceptive uncertainty due to activation of stretching muscles substantially exceeds the potential influence of general inhibition on proprioceptive input to limb state estimation during movement.

Because the RESIST condition failed to cause an increase in threshold in the first control experiment, the ASSIST effect was not due to elevated cutaneous or Golgi tendon organ mechanoreceptor activity (cf. Chapman et al., 1987; Nielson, 2004), which were undoubtedly elevated in both cases. Neither was the effect dependent on the direction of hand force, because forces experienced in passive movements (low thresholds) and ASSIST trials (high thresholds) were in the same direction. Similarly, the observed asymmetry of effect in the RESIST and ASSIST conditions precludes the possibility that the findings were due to a potential conflict between realized and expected sensory feedback driven by efference copy (and therefore expected to be present in all active conditions but not in the passive case). Instead, the increased proprioceptive uncertainty evident in the ACTIVE condition (primary experiment) and the ASSIST condition (first control experiment) likely reflect the influence of peripheral phenomena acting to increase variability in the proprioceptive signal itself. Muscle spindles are susceptible to output variability in both aand $y$-motorneuron systems (cf. Cordo et al., 1996), and so it is reasonable that increasing neural drive to lengthening muscles should increase variability in the transformation between muscle kinematics and afferent spike trains. This finding has relevance beyond mere perception of limb state (as studied here) because factors that degrade or otherwise change the transduction characteristics of muscle spindles

Experimental Brain Research, Vol. 204, No. 2 (July 2010): pg. 239-254. DOI. This article is (C Springer and permission has been granted for this version to appear in e-Publications@Marquette. Springer does not grant permission for this article to be further copied/distributed or hosted elsewhere without the express permission from Springer. 
NOT THE PUBLISHED VERSION; this is the author's final, peer-reviewed manuscript. The published version may be accessed by following the link in the citation at the bottom of the page.

must also influence other important sensorimotor behaviors that depend on limb state information (eg. motor planning and motor adaptation).

\section{Multi-task interference and its impact on perception}

The contralateral-hand key-pressing task and the visual channel both caused an increase in curvature detection threshold and response uncertainty. Both treatments likely shifted attention away from curvature detection, thereby distracting subjects from the task at hand. Distractions can have a profound impact on peripheral transmission of proprioceptive information, which may explain the detrimental effect on detection threshold. In a microneurographic study by Ribot-Ciscar and colleagues (2000), subjects relaxed as a pedal rotated the left ankle while microelectrodes sampled muscle spindle afferents from the peroneal nerve. After baseline recordings, subjects were to perform either mental calculations (eg addition of all odd numbers from 0 to 15 ) or to clench both fists. Both tasks required redirection of attention from the moving foot, and this increased both the sensitivity and baseline variability of type Ia muscle spindle firing rates in response to passive muscle stretch. If the CHAN and DUAL task treatments were to increase sensitivity and variability of spindle firing as in Ribot-Ciscar (2000), increased thresholds as observed in Control Experiment 2 suggest that the variability effect was more influential in modulating proprioceptive contributions to limb state estimation for perception because the putative increase in Ia spindle sensitivity did not suffice to maintain single-task performance. It is worth noting that prior studies found both treatments (the visual channel and diversion of attention) to reduce the rate and extent of motor adaptation (Scheidt et al. 2005 and Jordan and Thoroughman 2006, respectively), and thus these experimental manipulations may have a common influence on both conscious perception and implicit motor learning.

It is also possible that the DUAL and CHAN treatments have additional effects distinct from those previously reported for motor learning (cf. Wong and Henriques, 2009). Separate neural pathways project proprioceptive information to cerebral cortex (the dorsal column-medial lemniscal system) and the cerebellum (the cuneocerebellar tract), and thus different neural systems may be 
involved in multisensory integration for conscious perception and for the (unconscious) adaptive control of limb motion (cf. Rowland, 1985). The primary and second control experiment found that the visual channel had the effect of making subjects less decisive in their responses (the RU range increased). Response Uncertainty is thought to reflect indecision in the high-level transformation between percept and action (Kontsevich and Tyler, 1999). Results from the motion contrasts (primary and first control experiments) show it is possible to have an increase in proprioceptive uncertainty without an increase in $\mathrm{RU}$ and thus the two effects are at least partly independent. Because threshold and RU increased when subjects were required either to resolve an unusual sensory discordance (CHAN) or to simultaneously perform a distracting motor task with the contralateral hand (DUAL), and because threshold and RU increased further still when the treatments were combined, performance was not limited by a "bottleneck" in the allocation of attentional resources for these two treatments (cf. Bonnel and Hafter, 1998; Driver and Spence 1998; Treisman et al., 1980). We did however observe mutual, dual-task interference in that the key-press task caused threshold and RU to increase in the curvature detection task (Fig 4C) whereas key press error rate increased after movement onset and remained high throughout the decision interval (Fig 4B). These findings implicate central mechanisms of interference because the influence of peripheral events compromising proprioceptive reliability would not likely persist after movement ceased. Future studies testing perception and motor adaptation in the same subjects may be able to identify those factors contributing to proprioceptive uncertainty common to perception and action as well as factors specific to each function.

\section{Optimality of multisensory limb state estimation and its implications}

The computational problems that pertain to limb state estimation for perception also pertain to motor control and learning. Studies of motor adaptation to rotation, scaling and other distortions of visual feedback find that people readily adapt their reaches so that endpoint motions appear straight and smooth (Wolpert et al. 1994, 1995b; Flanagan and Rao 1995; Pine et al. 1996; Krakauer et al. 2000; Dingwell et al. 2002). While this compellingly shows that vision

Experimental Brain Research, Vol. 204, No. 2 (July 2010): pg. 239-254. DOI. This article is (C) Springer and permission has been granted for this version to appear in e-Publications@Marquette. Springer does not grant permission for this article to be further copied/distributed or hosted elsewhere without the express permission from Springer. 
also contributes importantly to limb state estimation (Sober and Sabes, 2003; Gritsenko et al., 2007), the mechanisms by which multisensory information is combined during reaching are incompletely understood. Vision and the mechanoreceptors contributing to proprioception have different intrinsic encoding and spatiotemporal filtering properties that make them preferentially sensitive to different aspects of motor performance (Beers et al., 1996, 1999; cf. Wolpert et al.,1995b). Vision encodes reach target location in egocentric coordinates (Admiraal et al. 2003; Crawford et al. 2004; Flanders and Soechting 1990; McIntyre et al. 1997; Soechting and Flanders 1989; Vetter et al., 1999; van den Dobbelsteen et al., 2004) whereas proprioceptors inherently encode the length and rate of lengthening of stretched muscles (Cordo et al., 1994; Matthews 1963, Soechting and Flanders 1989, Tillery et al, 1991), muscle force (Matthews, 1933; Houk and Henneman, 1967), as well as deformations and vibrations of the dermis and hair (see Prochazka 1996 for a review). The different information sources also have different intrinsic feedback delays (cf. Miall et al., 1985; Poladia et al., 2008; Rack, 1981), so there will always be "disagreement" between visual and proprioceptive feedback of limb position and movement. Such differences invariably lead to uncertainty in the limb state estimate. Early investigators proposed that people resolve visuo-proprioceptive conflict by ignoring proprioception in favor of visual cues (cf. Gibson, 1933; cf. Welch, 1978). If we assume that vision typically provides a more reliable estimate of limb state than proprioception, the experimental results are also consistent with models of optimal multisensory integration wherein the relative contributions of the different afferent channels are adjusted so as to favor reliable sensory modes and penalize less reliable ones (cf. Beers et al., 1996; Gharamani et al., 1997; Ernst and Banks, 2002; Koerding and Wolpert, 2004, Koerding et al., 2007).

Although proprioception alone contributed directly to curvature detection in these experiments, the visual channel had the indirect effect of increasing the effective proprioceptive uncertainty ( $\% \Delta \sigma_{\text {prop }}$ ) in both the primary and second control experiments. The visual channel provides feedback that is correlated in time with the ongoing movement but devoid of information related to actual hand path curvature and the component of path variability orthogonal to the straight-line reach. If subjects had ignored proprioception, they should have said that nearly all movements were straight. Only two of 20

Experimental Brain Research, Vol. 204, No. 2 (July 2010): pg. 239-254. DOI. This article is @ Springer and permission has been granted for this version to appear in e-Publications@Marquette. Springer does not grant permission for this article to be further copied/distributed or hosted elsewhere without the express permission from Springer. 
subjects did so, providing little support for the idea that vision was used to the exclusion of proprioception. Rather, curvature detection thresholds almost always assumed some intermediate value in the channel. So, while multimodal sensory information may be combined to minimize uncertainty in the overall perceived limb state, this optimization appears subject to the constraint that all information sources are treated with at least a modicum of disbelief.

Finally, our findings suggest an alternative way to think about motor performance optimization. When subjects learn to reach in the presence of novel force fields at the hand, they initially rely on muscle co-contraction to stabilize interaction with the environment (Milner and Cloutier, 1993; Franklin et al., 2003; Gribble et al., 2003). They gradually learn to anticipate the hand forces required to recover a straight-line reach in the perturbing environment while reducing cocontraction (Takahashi et al., 2001; Franklin et al., 2003). One explanation commonly provided for reduction in co-contraction is that excessive muscle activation is energetically inefficient (eg. the "wasted contraction" of Thoroughman and Shadmehr, 1999), with the implicit assumption that subjects optimize the energetics of movement (Nelson, 1983). We suggest instead that reducing co-contraction would improve the quality of proprioceptive feedback, thereby facilitating the evaluation of kinematic performance. This idea is synergistic with the hypothesis that the CNS modulates descending fusimotor output to increase information transmission within Ia afferents (Bergenheim et al. 1995). Although optimizing either muscle energetics or proprioceptive signal quality would lead to a reduction of co-contraction, there are no clear physiological mechanisms for transducing a measure of "excessive" muscle activity, whereas the quality of feedback could be assessed by evaluating the extent to which spindle responses correlate with other sensory estimates of task performance provided by visual feedback or predicted using efference copy and a forward model of the limb and its sensory organs (cf. Nelson 1996). Maximization of mutual information between sensory (and predictive) information streams may provide a compelling driving force for motor adaptation that could account for the apparent minimizations of effort, co-contraction or other "energetic" costs of control.

Experimental Brain Research, Vol. 204, No. 2 (July 2010): pg. 239-254. DOI. This article is (C Springer and permission has been granted for this version to appear in e-Publications@Marquette. Springer does not grant permission for this article to be further copied/distributed or hosted elsewhere without the express permission from Springer. 
Clinical observations of motor control following hemiparetic stroke often observe abnormal muscle synergy patterns that result in a dramatic increase in agonist/antagonist muscle co-contractions (Dewald, 1995), even in subjects with "intact" proprioceptive sense (Scheidt and Stoeckmann, 2007; Stoeckmann et al., 2009). The results of Exp 2 suggest that persistent muscle activations would degrade the quality of proprioceptive feedback and thus, adaptive reweighting of sensory information would lead to further dependence on reliable visual feedback for control and learning of movement. Because of lengthy delays associated with visual processing, hemiparetic subjects may increasingly resort to co-contraction to stabilize the hand during uncertain and potentially unstable interactions with the environment. This would further marginalize the value of residual proprioceptive function while reinforcing reliance on abnormal cocontraction. Thus, abnormal muscle activation synergies and the agonist/antagonist co-contractions they give rise to may represent a fundamental barrier to optimal sensorimotor integration and the effective re-learning of normal and/or compensatory motor commands post-stroke.

\section{Acknowledgments}

This work was supported by: Whitaker Foundation RG010157, National Science Foundation BES 0238442, National Institutes of Health R24 HD39627 and R01 HD053727, the Alvin W. and Marion Birnschein Foundation and the Falk Foundation Medical Trust. We also thank members of the Neuromotor Control Lab at Marquette University for helpful comments on a previous version of this manuscript.

\section{Appendix}

\section{The ideal observer and decision process model}

In the experiments described here, proprioception alone is informative of whether the hand path is actually straight or curved. Each movement produces proprioceptive signals providing information the subject uses to classify his or her percept. We model the percept as a point on an underlying continuous dimension with units of curvature $\left[\mathrm{m}^{-1}\right]$ (the discrimination axis; Fig A1, top). We assume that sensation is imperfect and influenced by noises that are Gaussian with

Experimental Brain Research, Vol. 204, No. 2 (July 2010): pg. 239-254. DOI. This article is (C Springer and permission has been granted for this version to appear in e-Publications@Marquette. Springer does not grant permission for this article to be further copied/distributed or hosted elsewhere without the express permission from Springer. 
zero mean. By definition, the evidence provided by curved trials is, on average, greater than that provided by straight trials. Fig A1 (top) shows two distribution functions indicating the likelihood of evidence under the two alternatives (curved: C, red; straight: S, black). The subject's task is to decide which distribution the evidence was drawn from. We assume that subjects are stationary in their understanding of "straight" and therefore align the mean of the $S$ distribution with the origin. It seems reasonable to expect that the same noises affect proprioceptive cues regardless of path. We therefore model the task as an equal-variance Gaussian signal discrimination process (Wickens, 2002) wherein $\sigma^{2}{ }_{c}=\sigma^{2}$ Finally, we allow that the magnitude of noises influencing perception may vary across experimental treatments.

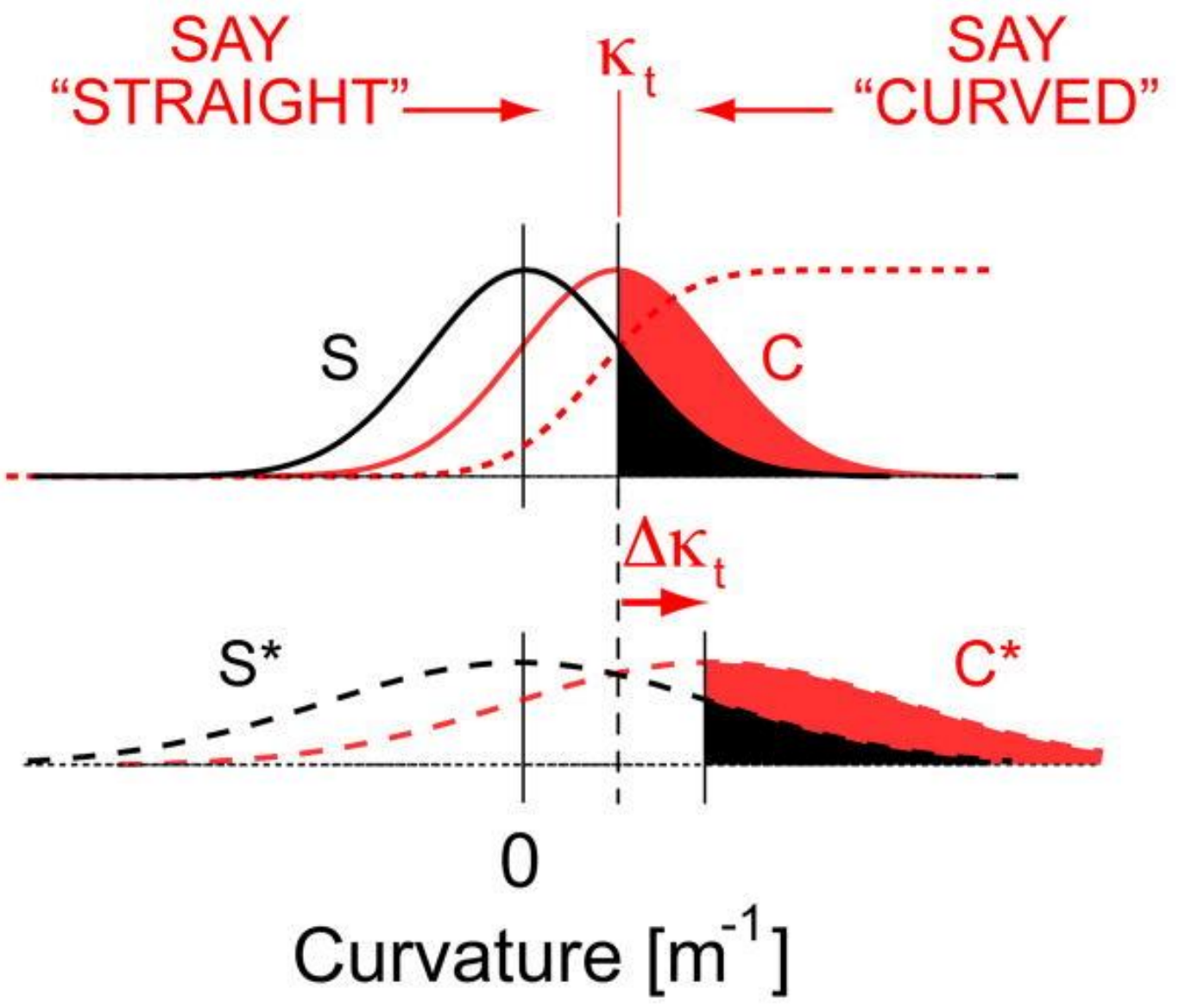

Figure A-1 The equal-variance Gaussian model of curvature discrimination used in this study. Top: the nominal case where proprioceptive signals providing evidence for curvature (red, ' $C$ ') exceed those supporting a 'straight' response (black, ' $S$ ') by an unknown critical proportion at detection threshold, $\mathrm{k}_{\mathbf{t}}$. Bottom: Applying the same

Experimental Brain Research, Vol. 204, No. 2 (July 2010): pg. 239-254. DOI. This article is ( Springer and permission has been granted for this version to appear in e-Publications@Marquette. Springer does not grant permission for this article to be further copied/distributed or hosted elsewhere without the express permission from Springer. 
criterion to the case where inherent variability has increased by the same amount in both $\mathrm{C}^{*}$ and $\mathrm{S}^{*}$ distributions results in an increase in $\mathrm{K}_{\mathbf{t}}$ (i.e. the ratio of red:black shaded areas is the same for both sets of curves).

An ideal observer chooses the distribution ( $\mathrm{S}$ or $\mathrm{C}$ ) from which a sensation originated based on whether the ratio of evidence for the two alternatives exceeds some critical criterion value (cf. Green and Swets, 1966). Under an equal variance Gaussian model, the criterion corresponds to a distance from the origin (measured in units of standard deviations) above which the presence of signal is indicated reliably. When fit to experimental data, Eqn 1 (Fig A1 top, dashed trace) provides an estimate of $\mathrm{K}_{\mathrm{t}}$, the value above which movements are identified as curved. The likelihood ratio that defines criterion depends on the unknown variability of the $S$ and $C$ curves, and so the actual criterion is unknown. However, as there is no a priori reason to prefer signal or noise responses, we assume that criterion does not change from one trial block to the next (i.e. the subject does not need more evidence for the presence of curvature in one case over another). As shown below, a change in the underlying distribution variance will shift $\kappa_{t}$ proportionally (Fig A1, bottom), allowing a comparison of relative impact of experimental treatment on the inherent variability of proprioceptive contribution to limb state estimation.

Signal detection theory provides a measure of signal discriminability $\left(d^{\prime}\right)$ relating pairs of distributions as in Fig $A 1 . d^{\prime}$ is 0 when the distributions are identical and large when widely separated. For the equal-variance model (Wickens, 2002):

$$
d^{\prime}=\frac{\mu_{C}}{\sigma_{S}}
$$

$\mu_{c}$ corresponds to the expected value of evidence observed when the hand path is curved and ${ }_{2}$ is the variance of noises influencing the proprioceptive estimate of limb state. $d^{\prime}$ is determined only by the signal strength and the subject's receptivity to that signal; it is not influenced by subjective decision criteria (Green and Swets, 1966; Wickens, 2002). Because of this invariance, we equate the value of $d^{\prime}$ across experimental conditions. Under the stationary criterion 
assumption, we estimate $\mu_{C}$ as the value $\kappa_{t}$ for each experimental condition because this is the stimulus intensity sufficient for the signalto-noise likelihood ratio to just exceed criterion. Using this decision process model, it is easy to show that changes in threshold reflect changes in how subjects use proprioceptive information to detect curvature; the effective change in the subject's internal estimate of the variability of proprioception ( $\% \Delta \sigma_{\text {prop }}$ ) caused by a treatment relative to the variability observed without the treatment is proportional to the ratio of thresholds obtained in the two cases:

$$
{ }_{0} \Delta \sigma_{\text {prop }} \cong 100\left(\frac{\kappa_{t_{\text {treatment }}}}{\kappa_{t_{\text {no_treatment }}}}-1\right) .
$$

\section{References}

1. Admiraal MA, Keijsers NL, Gielen CC. Interaction between gaze and pointing toward remembered visual targets. J Neurophysiol. 2003;90:2136-2148.

2. Beers RJv, Sittig AC, Gon JJDvd. How humans combine simultaneous proprioceptive and visual position information. Exp Brain Res. $1996 ; 111: 253-261$.

3. Beers RJv, Sittig AC, Gon JJDvd. Integration of proprioceptive and visual position information: An experimentally supported model. J Neurophysiol. 1999;81:1355-1364.

4. Bergenheim $M$, Johansson $H$, Pedersen J. The role of the gamma-system for improving information transmission in populations of Ia afferents. Neurosci Res. 1995;23:207-215.

5. Bonnel A, Hafter ER. Divided attention between simultaneous auditory and visual signals. Perceptual Psychophysics. 1998;60:179-190.

6. Capaday C, Cooke JD. The effects of muscle vibration on the attainment of intended final position during voluntary human arm movement. Exp Brain Res. 1981;42:228-230.

7. Chapman CE, Bushnell MC, Miron D, Duncan GH, Lund JP. Sensory perception during movement in man. Exp Brain Res. 1987;68:516524.

Experimental Brain Research, Vol. 204, No. 2 (July 2010): pg. 239-254. DOI. This article is @ Springer and permission has been granted for this version to appear in e-Publications@Marquette. Springer does not grant permission for this article to be further copied/distributed or hosted elsewhere without the express permission from Springer. 
NOT THE PUBLISHED VERSION; this is the author's final, peer-reviewed manuscript. The published version may be accessed by following the link in the citation at the bottom of the page.

8. Cordo P, Carlton L, Bevan L, Carlton M, Kerr GK. Proprioceptive coordination of movement sequences: role of velocity and position information. J Neurophysiol. 1994;71:1848-1861.

9. Cordo P, Inglis JT, Verschueren S, Collins JJ, Merfeld DM, Rosenblum S, Buckley S, Moss F. Noise in human muscle spindles. Nature. 1996;383:769-770.

10. Cornsweet TN. The staircase method in psychophysics. Am J Psychol. $1962 ; 75: 485-491$.

11. Crawford JD, Medendorp WP, Marotta JJ. Spatial transformations for eyehand coordination. J Neurophysiol. 2004;92:10-19.

12. Dewald JP, Pope PS, Given JD, Buchannan TS, Rymer WZ. Abnormal muscle coactivation patterns during isometric torque generation at the elbow and shoulder in hemiparetic subjects. Brain. 1995;118:495510.

13. Desmurget M, Grafton S. Forward modeling allows feedback control for fast reaching movements. $\operatorname{Tr}$ Cog Sci. 2000;4(11):423-431.

14. Dingwell JB, Mah CD, Mussa-Ivaldi FA. Manipulating objects with internal degrees of freedom: evidence for model-based control. J Neurophysiol. 2002; $88: 222-235$.

15. Dizio P, Lackner JR. Congenitally blind individuals rapidly adapt to Coriolis force perturbations of their reaching movements. J Neurophysiol. $2000 ; 84: 2175-2180$.

16. Driver J, Spence C. Crossmodal Attention. Current Opinion in Neurobiology. 1998;8:245-253.

17. Dufresne JR, Soechting JF, Terzuolo CA. Modulation of the myotatic reflex gain in man during intentional movements. Brain Res. 1980;193:6784.

18. Ernst MO, Banks MS. Humans integrate visual and haptic information in a statistically optimal fashion. Nature. 2002;415:429-433.

19. Flanagan JR, Rao AK. Trajectory adaptation to a nonlinear visuomotor transformation: Evidence of motion planning in visually perceived space. J Neurophysiol. 1995;74(5):2174-2178.

20. Flanders M, Soechting JF. Parcellation of sensorimotor transformations for arm movements. J Neurosci. 1990;10:2420-2427.

Experimental Brain Research, Vol. 204, No. 2 (July 2010): pg. 239-254. DOI. This article is (C Springer and permission has been granted for this version to appear in e-Publications@Marquette. Springer does not grant permission for this article to be further copied/distributed or hosted elsewhere without the express permission from Springer. 
21. Franklin DW, Osu R, Burdet E, Kawato M, Milner TE. Adaptation to stable and unstable dynamics achieved by combined impedance control and inverse dynamics model. J Neurophysiol. 2003;90:3270-3282.

22. Gandevia SC. Kinesthesia: roles for afferent signals and motor commands. In: Rowell LB, Shepherd JT, editors. Handbook of Physiology. Oxford UK; Oxford: 1996. pp. 128-172.

23. Gescheider GA. Psychophysics - the fundamentals. New Jersey: Lawrence Erlbaum Associates; 1997.

24. Ghahramani Z. PhD Thesis. Dept. of Brain and Cognitive Sciences, Massachusetts Institute of Technology; Cambridge, MA: 1995. Computation and Psychophysics of sensorimotor integration.

25. Ghahramani Z, Wolpert DM, Jordan MI. Computational models of sensorimotor integration. In: Morasso PG, Sanguineti V, editors. SelfOrganization, Computational Maps and Motor Control. North-Holland Publishing; Amsterdam: 1997. pp. 117-147.

26. Ghez C, Gordon J, Ghilardi MF. Impairments of reaching movements in patients without proprioception. II Effects of visual information on accuracy. J Neurophysiol. 1995;73:361-372. [PubMed]

27. Ghez C, Krakauer JW, Sainburg RL, Ghilardi M-F. Spatial representations and internal models of limb dynamics in motor learning. In: Gazzaniga MS, editor. The New Cognitive Neurosciences. 2. Cambridge, Mass: The MIT Press; 1999. pp. 501-514.

28. Ghez C, Pisa M. Inhibition of afferent transmission in cuneate nucleus during voluntary movement in the cat. Brain Research. 1972;40:145151. [PubMed]

29. Gibson JJ. Adaptation, after-effect and contrast in the perception of curved lines. J Exp Psychology. 1933;16:1-31.

30. Gordon J, Ghilardi MF, Ghez C. Impairments of reaching movements in patients without proprioception. I. Spatial errors. J Neurophysiol. 1995;73:247-360. [PubMed]

31. Green DM, Swets JA. Signal Detection Theory and Psychophysics. New York: Wiley; 1966.

32. Gribble PL, Mullin LI, Cothros N, Mattar A. Role of cocontraction in arm movement accuracy. J Neurophysiol. 2003;89:2396-2405. [PubMed]

33. Gritsenko V, Krouchev NI, Kalaska JF. Afferent input, efference copy, signal noise, and biases in perception of joint angle during active

Experimental Brain Research, Vol. 204, No. 2 (July 2010): pg. 239-254. DOI. This article is (C Springer and permission has been granted for this version to appear in e-Publications@Marquette. Springer does not grant permission for this article to be further copied/distributed or hosted elsewhere without the express permission from Springer. 
NOT THE PUBLISHED VERSION; this is the author's final, peer-reviewed manuscript. The published version may be accessed by following the link in the citation at the bottom of the page.

versus passive elbow movements. J Neurophysiol. 2007;98:11401154. [PubMed]

34. Hagbarth KE, Valbo AO. Activity in human muscle afferents during muscle stretch and contraction. Elextroencephalogr Clin Neurophysiol. 1969;26:341-XXX. [PubMed]

35. Hamilton AFdC, Jones KE, Wolpert DM. The scaling of motor noise with muscle strength and motor unit number in humans. Exp Brain Res. 2004;157:417-430. [PubMed]

36. Haruno M, Wolpert DM, Kawato M. MOSAIC Model for Sensorimotor Learning and Control. Neural Computation. 2001;13:2201-2220. [PubMed]

37. Hasan Z. A model of spindle afferent response to muscle stretch. J Neurophysiol. 1983;49(4):989-1006. [PubMed]

38. Henriques DYP, Soechting JF. Bias and sensitivity in the haptic perception of geometry. Exp Brain Res. 2003;150:95-108. [PubMed]

39. Houk JC, Henneman E. Responses of Golgi tendon organs to active contractions of the soleus muscle of the cat. J Neurophysiol. $1967 ; 30(3): 466$.

40. Houk JC, Rymer WZ. Neural control of muscle length and tension. In: Brooks VB, editor. Handbook of Physiology. Baltimore: American Physiological Society; 1981. pp. 257-323.

41. Houk JC, Rymer WZ, Crago PE. Dependence of dynamic response of spindle receptors on muscle length and velocity. J Neurophysiol. $1981 ; 46(1): 143-166$.

42. Hultborn H. State-dependent modulation of sensory feedback. J Physiology. 2001;533:5-13.

43. Ingram HA, van Donkelaar $\mathrm{P}$, Cole J, Vercher JL, Gauthier GM, Miall RC. The role of proprioception and attention in a visuomotor adaptation task. Exp Brain Res. 2000;132(1):114-126.

44. Jones KE, Hamilton AFdC, Wolpert DM. Sources of signal-dependent noise during isometric force production. J Neurophysiol. 2002;88:15331544. [

45. Kakuda N, Nagaoka M. Dynamic response of human muscle spindle afferents to stretch. J Physiol. 1998;513(2):621-628.

Experimental Brain Research, Vol. 204, No. 2 (July 2010): pg. 239-254. DOI. This article is @ Springer and permission has been granted for this version to appear in e-Publications@Marquette. Springer does not grant permission for this article to be further copied/distributed or hosted elsewhere without the express permission from Springer. 
NOT THE PUBLISHED VERSION; this is the author's final, peer-reviewed manuscript. The published version may be accessed by following the link in the citation at the bottom of the page.

46. Kearney RE, Lortie M, Stein RB. Modulation of stretch reflexes during imposed walking movements of the human ankle. J Neurophysiol. $1999 ; 81: 2893-2902$.

47. Koerding KP, Wolpert DM. Bayesian integration in sensorimotor learning. Nature. 2004;427:244-247.

48. Koerding KP, Beierholm U, Ma WJ, Quartz S, Tenenbaum JB, Shams L. Causal inference in multisensory perception. PLOS ONE. 2007;2(9):e943. doi: 10.1371/journal.pone.0000943.

49. Kontsevich LL, Tyler CW. Distraction of attention and the slope of the psychometric function. J Opt Soc Am A. 1999;16(2):217-222.

50. Krakauer JW, Pine ZM, Ghilardi M-F, Ghez C. Learning of visuomotor transformations for vectorial planning of reaching trajectories. J Neurosci. 2000;20(23):8916-8924.

51. Lackner JR, Dizio P. Rapid adaptation to Coriolis force perturbations of arm trajectory. J Neurophysiol. 1994;72:299-313.

52. Lillis KP, Scheidt RA. IEEE EMBS Soc. Cancun MX: 2003. Sensitivity to hand path curvature during reaching.

53. Matthews BHC. Nerve endings in mammalian muscle. J Physiol Lond. $1933 ; 78: 1-53$.

54. Matthews PBC. The response of de-efferented muscle spindle receptors to stretching at different velocities. J Physiol. 1963;168:660-678.

55. Matthews PBC. Observations on the automatic compensation of reflex gain on varying the pre-existing level of motor discharge in man. J Physiol. 1986;374:73-90.

56. McCloskey . Differences between the senses of position and movement... Brain Res. 1973.

57. McIntyre J, Stratta F, Lacquaniti F. Viewer-centered frame of reference for pointing to memorized targets in three-dimensional space. J Neurophysiol. 1997;78:1601-1618.

58. Miall RC, Weir DJ, Stein JF. Visuomotor tracking with delayed visual feedback. J Neurosc. 1985;16:511-522.

59. Miall RC, Weir DJ, Wolpert DM, Stein JF. Is the cerebellum a Smith predictor? J Mot Behav. 1993;25:203-216.

60. Milner TE, Cloutier C. Compensating for mechanically unstable loading in voluntary wrist movement. Exp Brain Res. 1993;94

Experimental Brain Research, Vol. 204, No. 2 (July 2010): pg. 239-254. DOI. This article is (C Springer and permission has been granted for this version to appear in e-Publications@Marquette. Springer does not grant permission for this article to be further copied/distributed or hosted elsewhere without the express permission from Springer. 
NOT THE PUBLISHED VERSION; this is the author's final, peer-reviewed manuscript. The published version may be

accessed by following the link in the citation at the bottom of the page.

61. Morasso P. Spatial control of arm movements. Exp Brain Res. $1981 ; 42: 223-227$.

62. Nelson W. Physical principles for economies of skilled movements. Biol Cybern. 1983;46:135-147.

63. Nelson RJ. Interactions between motor commands and somatic perception in sensorimotor cortex. Curr Opin in Neurobiol. 1996;6:801-810.

64. Nielsen JB. Sensorimotor integration at spinal level as a basis for muscle coordination during voluntary movement in humans. J Appl Physiol. 2004;96:1961-1967.

65. Perreault EJ, Chen K, Trumbower RD, Lewis G. Interactions with compliant loads alter stretch reflex gains but not intermuscular coordination. J Neurophysiol. 2008;99:2101-2113.

66. Pine ZM, Krakauer JW, Gordon J, Ghez C. Learning of scaling factors and reference axes for reaching movements. NeuroReport. 1996;7:23572361.

67. Poladia C, Scheidt RA, Beardsley S. Abstr Soc Neurosci. Vol. 32. Washington, DC: 2008. Systems Identification of Sensory-Motor Control for Visually Guided Wrist Movements.

68. Prochazka A. Proprioceptive feedback and movement regulation. In: Rowell LB, Shepard JT, editors. Handbook of Physiology - Section 12. New York: Oxford University Press; 1996. pp. 89-127.

69. Rack PMH. Handbook of Physiology The Nervous System. sect 1. II. Bethesda, MD: Am. Physiol. Soc; 1981. Limitations of somatosensory feedback in control of posture and movement; pp. 229-256. part 1, chap. 7.

70. Redding GM, Rader SD, Lucas DR. Cognitive load and prism adaptation. J Mot Behav. 1992;24:238-246.

71. Ribot-Ciscar E, Rossi-Durand C, Roll J-P. Increased muscle spindle sensitivity to movement during reinforcement manoeuvres in relaxed human subjects. J Physiol. 2000;523(1):271-282.

72. Roll JP, Gilhodes JC. Proprioceptive sensory codes mediating movement trajectory perception: human hand vibration-induced drawing illusions. Can J Physiol Pharmacol. 1995;73:295-305.

73. Rowland LP. Clinical syndromes of the spinal cord. In: Kandel ER, Schwartz JH, editors. Principles of Neuroscience. 2. pp. 469-477.

Experimental Brain Research, Vol. 204, No. 2 (July 2010): pg. 239-254. DOI. This article is (C Springer and permission has been granted for this version to appear in e-Publications@Marquette. Springer does not grant permission for this article to be further copied/distributed or hosted elsewhere without the express permission from Springer. 
NOT THE PUBLISHED VERSION; this is the author's final, peer-reviewed manuscript. The published version may be accessed by following the link in the citation at the bottom of the page.

74. Sainburg RL, Ghilardi MF, Poizner H, Ghez C. Control of limb dynamics in normal subjects and patients without proprioception. J Neurophysiol. $1995 ; 73: 820-835$.

75. Salinas E. Fast remapping of sensory stimuli onto motor actions on the basis of contextual modulation. J Neuroscience. 2004;24:1113-1118.

76. Scheidt RA, Conditt MA, Reinkensmeyer DJ, Mussa-Ivaldi FA. Persistence of motor adaptation during constrained, multi-joint, arm movements. J Neurophysiology. 2000;84:853-862.

77. Scheidt RA, Conditt M, Secco EL, Mussa-Ivaldi FA. Interaction of visual and proprioceptive feedback during adaptation of human reaching movements. J Neurophysiol. 2005;93:3200-13.

78. Scheidt RA, Dingwell J, Mussa-Ivaldi FA. Learning to Move Amid Uncertainty. Journal of Neurophysiology. 2001;86:971-985.

79. Scheidt RA, Kertesz AE. Temporal and spatial aspects of sensory interactions during human fusional response. Vision Research. $1992 ; 33: 1259-1270$

80. Scheidt RA, Rymer WZ. Control strategies for the transition from multijoint to single-joint arm movements studied using a simple mechanical constraint. J Neurophysio. 2000;83:1-12.

81. Scheidt RA, Stoeckmann T. Reach adaptation and final position control amid environmental uncertainty following stroke. J Neurophysiol. 2007;97:2824-2836.

82. Schmidt RA, Zelaznik H, Hawkins B, Frank JS, Quinn JTJ. Motor-output variability: a theory for the accuracy of rapid motor acts. Psychol Rev. $1979 ; 47: 415-451$.

83. Seki K, Perlmutter SI, Fetz EE. Sensory input to primate spinal cord is presynaptically inhibited during voluntary movement. Nature Neuroscience. 2003;6:1309-1316.

84. Shadmehr R, Mussa-Ivaldi FA. Adaptive representation of dynamics during learning of a motor task. Journal of Neuroscience. $1994 ; 14: 3208-3224$

85. Sinkjaer T, Andersen JB, Larsen B. Soleus stretch reflex modulation during gait in humans. J Neurophysiol. 1996;76:1112-1120.

86. Sittig AC, Gon JJDvd, Gielen CC. The contribution of afferent information on position and velocity to the control of slow and fast human forearm movements. Exp Brain Res. 1987;67:33-40.

Experimental Brain Research, Vol. 204, No. 2 (July 2010): pg. 239-254. DOI. This article is (C Springer and permission has been granted for this version to appear in e-Publications@Marquette. Springer does not grant permission for this article to be further copied/distributed or hosted elsewhere without the express permission from Springer. 
NOT THE PUBLISHED VERSION; this is the author's final, peer-reviewed manuscript. The published version may be accessed by following the link in the citation at the bottom of the page.

87. Slifkin $A B$, Newell KM. Variability and noise in continuous force production. J Mot Behav. 2000;32(2):141-150.

88. Smith MA, Ghazizadeh A, Shadmehr R. Interacting adaptive processes with different time scales underlie short-term motor learning. PLoS Biol. 2006;4:e179.

89. Sober SJ, Sabes PN. Multisensory integration during motor planning. J Neurosci. 2003;23:6982-6992.

90. Soechting JF, Flanders M. Sensorimotor representations for pointing to targets in three-dimensional space. Journal of Neurophysiology. $1989 ; 62: 582-594$.

91. Soso MJ, Fetz EE. Responses of identified cells in postcentral cortex of awake monkeys during comparable active and passive joint movements. J Neurophysiol. 1980;43(4):1090-1111.

92. Stoeckmann T, Sullivan K, Scheidt RA. (2009) Elastic, viscous, and mass load effects on post-stroke muscle recruitment and cocontraction during reaching: A pilot study. Phys Ther. 2009;89(7):665-678. [PMC free article] [PubMed]

93. Sutton G, Sykes K. The variation of hand tremor with force in healthy subjects. J Physiol (Lond) 1967;191:699-711.

94. Takahashi C, Scheidt RA, Reinkensmeyer DJ. Impedance control and internal model formation when reaching in a randomly varying dynamical environment. J Neurophysiol. 2001;86:1047-1051.

95. Taylor JA, Thoroughman KA. Divided attention impairs human motor adaptation but not feedback control. J Neurophysiol. 2006;98:317326.

96. Taylor JA, Thoroughman KA. Motor adaptation scaled by the difficulty of a secondary cognitive task. PLoS ONE. 2007;3(6):e2485. doi: $10.1371 /$ journal.pone.0002485.

97. Thoroughman KA, Shadmehr R. EMG correlates of learning internal models of reaching movements. J Neuroscience. 1999;19:8573-8588.

98. Thoroughman KA, Shadmehr R. Learning of action through adaptive combination of motor primitives. Nature. 2000;407:742-747.

99. Tillery SI, Flanders M, Soechting JF. A coordinate system for the synthesis of visual and kinesthetic information. Journal of Neurophysiology. $1991 ; 11: 770-778$.

Experimental Brain Research, Vol. 204, No. 2 (July 2010): pg. 239-254. DOI. This article is (C Springer and permission has been granted for this version to appear in e-Publications@Marquette. Springer does not grant permission for this article to be further copied/distributed or hosted elsewhere without the express permission from Springer. 
NOT THE PUBLISHED VERSION; this is the author's final, peer-reviewed manuscript. The published version may be accessed by following the link in the citation at the bottom of the page.

100. Todorov E, Jordan MI. Optimal feedback control as a theory of motor coordination. Nat Neurosci. 2002;5:1226-1235.

101. Treisman AM, Gelade G. A feature-integration theory of attention. Cogn Psychol. 1980;12:97-136.

102. van den Dobbelsteen JJ, Brenner E, Smeets JB. Body-centered visuomotor adaptation. J Neurophysiol. 2004;92:416-423.

103. Verschueren SMP, Swinnen SP, Cordo PJ, Dounskaia NV. Proprioceptive control of multijoint movement: unimanual circle drawing. Exp Brain Res. $1999 ; 127: 171-181$.

104. Vetter P, Goodbody SJ, Wolpert DM. Evidence for an eye-centered spherical representation of the visuomotor map. J Neurophysiol. 1999;81:935-959.

105. Voss M, Ingram JN, Haggard P, Wolpert DM. Sensorimotor attenuation by central motor command signals in the absence of movement. Nat Neurosci. 2006;9(1):26-27.

106. Voss M, Ingram JN, Wolpert DM, Haggad P. Mere expectation to move causes attenuation of sensory signals. PLOS One. 2008;3(8):e2866.

107. Welch RB. Perceptual Modification: Adapting to altered sensory environments. New York: Academic Press; 1978.

108. Wickens TD. Elementary Signal Detection Theory. New York: Oxford University Press; 2002.

109. Williams SR, Chapman CE. Time Course and Magnitude of MovementRelated Gating of Tactile Detection in Humans. II. Effects of Stimulus Intensity. J Neurophysiol. 2000;84:863-875.

110. Wolpert DM, Ghahramani Z, Jordan MI. Perceptual distortion contributes to the curvature of human reaching movements. Experimental Brain Research. 1994;98:153-156.

111. Wolpert DM, Ghahramani Z, Jordan MI. An internal model for sensorimotor integration. Science. 1995a;269:1880-1882.

112. Wolpert DM, Ghahramani Z, Jordan MI. Are arm trajectories planned in kinematic or dynamic coordinates? An adaptation study. Experimental Brain Research. 1995b;103:460-470.

113. Wolpert DM, Kawato M. Multiple paired forward and inverse models for motor control. Neur Net. 1998;11:1317-1329.

Experimental Brain Research, Vol. 204, No. 2 (July 2010): pg. 239-254. DOI. This article is (C Springer and permission has been granted for this version to appear in e-Publications@Marquette. Springer does not grant permission for this article to be further copied/distributed or hosted elsewhere without the express permission from Springer. 
NOT THE PUBLISHED VERSION; this is the author's final, peer-reviewed manuscript. The published version may be accessed by following the link in the citation at the bottom of the page.

114. Wong T, Henriques DYP. Visuomotor adaptation does not recalibrate kinesthetic sense of felt hand path. J Neurophysiol. 2009;101:614623.

115. Zackowski K, Dromerick A, Sahrmann S, Thach W, Bastian A. How do strength, sensation, spasticity and joint individuation relate to the reaching deficits of people with chronic hemiparesis? Brain.

2004; 127:1035-1046.

\section{About the Authors}

Robert A. Scheidt: Department of Biomedical Engineering, Marquette

University, Olin Engineering Center, 303, P.O. Box 1881, Milwaukee, WI 53201-1881

Telephone: (414) 288-6124, Fax: (414) 288-7938,

Email: scheidt@ieee.org

Experimental Brain Research, Vol. 204, No. 2 (July 2010): pg. 239-254. DOI. This article is @ Springer and permission has been granted for this version to appear in e-Publications@Marquette. Springer does not grant permission for this article to be further copied/distributed or hosted elsewhere without the express permission from Springer. 